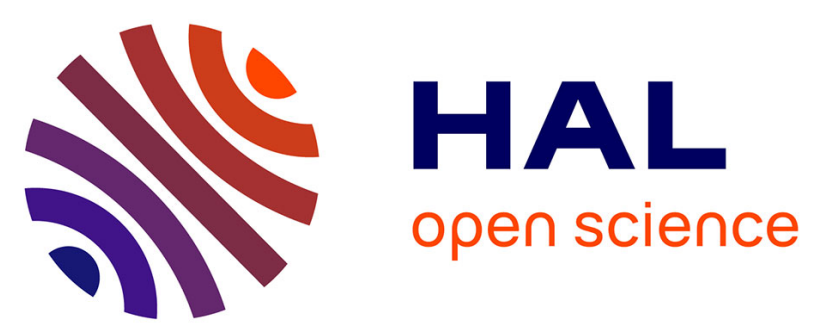

\title{
Regulation of Nicotiana tabacum osmotic stress-activated protein kinase and its cellular partner GAPDH by nitric oxide in response to salinity
}

Izabela Wawer, Maria Bucholc, Jéremy Astier, Anna Anielska-Mazur, Jennifer Dahan, Anna Kulik, Aleksandra Wyslouch-Cieszynska, Monika Zaręba-Koziol, Ewa Krzywinska, Michal Dadlez, et al.

\section{To cite this version:}

Izabela Wawer, Maria Bucholc, Jéremy Astier, Anna Anielska-Mazur, Jennifer Dahan, et al.. Regulation of Nicotiana tabacum osmotic stress-activated protein kinase and its cellular partner GAPDH by nitric oxide in response to salinity. Biochemical Journal, 2010, 429 (1), pp.73-83. 10.1042/BJ20100492 . hal-00491634

\author{
HAL Id: hal-00491634 \\ https://hal.science/hal-00491634
}

Submitted on 14 Jun 2010

HAL is a multi-disciplinary open access archive for the deposit and dissemination of scientific research documents, whether they are published or not. The documents may come from teaching and research institutions in France or abroad, or from public or private research centers.
L'archive ouverte pluridisciplinaire HAL, est destinée au dépôt et à la diffusion de documents scientifiques de niveau recherche, publiés ou non, émanant des établissements d'enseignement et de recherche français ou étrangers, des laboratoires publics ou privés. 


\section{Regulation of Nicotiana tabacum osmotic stress-activated protein kinase and its cellular partner GAPDH by nitric oxide in response to salinity}

Izabela Wawer $^{1,2^{*}}$, Maria Bucholc ${ }^{2 *}$, Jéremy Astier ${ }^{1}$, Anna Anielska-Mazur ${ }^{2}$, Jennifer Dahan ${ }^{1}$, Anna Kulik ${ }^{2}$, Aleksandra Wysłouch-Cieszynska ${ }^{2}$, Monika Zaręba-Kozioł ${ }^{2}$, Ewa Krzywinska ${ }^{2}$, Michal Dadlez ${ }^{2}$, Grażyna Dobrowolska, ${ }^{2, \#}$ and David Wendehenne ${ }^{1, \#}$

${ }^{1}$ UMR INRA 1088/CNRS 5184/Université de Bourgogne, Plante-Microbe-Environnement, 17 rue Sully, 21065 Dijon cedex, France;

${ }^{2}$ Institute of Biochemistry and Biophysics, Polish Academy of Sciences, ul. Pawinskiego 5a, 02-106 Warsaw, Poland;

*Both authors contributed equally to this work.

"To whom correspondence should be addressed:

G. Dobrowolska: Tel: 48-22-5925717; Fax: 48-22-6584636; Email: dobrowol@ibb.waw.pl

D. Wendehenne: Tel.: 33-380-693722; Fax: 33-380-693226; Email: wendehen@ dijon.inra.fr

Keywords: Glyceraldehyde 3-phosphate dehydrogenase, nitric oxide, NtOSAK, phosphorylation, S-nitrosylation, SnRK2 


\begin{abstract}
Several studies focused on elucidating the mechanism of nitric oxide (NO) signalling in plant cells highlighted that its biological effects are partly mediated by protein kinases. Identity of these kinases and details of how NO modulates their activities, however, remain poorly investigated. Here, we have attempted to clarify the mechanisms underlying NO action in regulation of Nicotiana tabacum osmotic stress-activated protein kinase (NiOSAK), a member of the SNF1-related protein kinase 2 family. We found that in tobacco BY-2 cells exposed to salt stress, NtOSAK is rapidly activated partly through a NO-dependent process. This activation, as well as the one observed following treatment of BY-2 cells with the NO donor DEA/NO, involved the phosphorylation of two residues located in the kinase activation loop, one being identified as Ser-158. Our results indicate that NtOSAK does not undergo the direct chemical modifications of its Cys residues by S-nitrosylation. Using a coimmunoprecipitation-based strategy, we identified several proteins present in immunocomplex with NtOSAK in salt-treated cells including the glycolytic enzyme glyceraldehyde 3-phosphate dehydrogenase (GAPDH). Our results indicate that NtOSAK directly interacts with GAPDH in planta. Furthermore, in response to salt, GAPDH showed a transient increase of its S-nitrosylation level which was correlated with the time course of NtOSAK activation. However, GADPH S-nitrosylation did not influence its interaction with NtOSAK and did not impact the activity of the protein kinase. Taken together, the results support the hypothesis that NtOSAK and GAPDH form a cellular complex and that both proteins are regulated directly or indirectly by NO.
\end{abstract}




\section{INTRODUCTION}

Over the past years, the free radical gas nitric oxide (NO) has become established as an intracellular messenger that affects signalling pathways involved in the plant cell response to various biotic and abiotic stimuli including hormones, pathogens and derived pathogenassociated molecular patterns (PAMPs), heavy metals or salt [1-3]. The emerging picture is that NO exerts part of its biological actions by modulating the activity of a wide array of proteins, some being involved in the production or in the mobilization of cellular messengers such as $\mathrm{H}_{2} \mathrm{O}_{2}, \mathrm{Ca}^{2+}$ and cyclic GMP [4-6]. Ultimately, these processes might influence the expression of numerous NO target genes, thus leading to an adaptive response [7]. Mechanistically, a growing body of evidence indicate that NO impacts the activity of target proteins by the direct chemical modification of transition metals and critical residues, preferentially Cys and Tyr residues. In particular, proteins regulated by S-nitrosylation, that is the reversible coupling of an NO moiety to a critical Cys-residue (forming an S-nitrosothiol), have been recently identified in Arabidopsis thaliana. These include glycine decarboxylase [8], the glycolytic enzyme glyceraldehydes 3-phosphate dehydrogenase (GAPDH) [9,10], methionine adenosyltransferase 1 [11]; metacaspase 9 [12], NPR 1 [13], the salicylic acidbinding protein 3 [14], peroxiredoxin II [15] and the transcription factor AtMYB2 [16]. These proteins are related to cell death, defence responses and metabolism. Depending on the proteins, S-nitrosylation promotes or inhibits their activity.

Several studies highlighted a role for protein kinases in conveying NO effects in plants. The bulk of the evidence for protein kinases regulation by NO has mainly relied on the ability of NO donors to trigger protein kinase activities in cell suspensions and/or tissues of various species [17]. Similarly, NO scavengers and inhibitors of NO synthesis were shown to impair the activation of protein kinases triggered by PAMPs [18], abscisic acid (ABA) [19], auxin [20] and sorbitol-induced hyper-osmotic stress [21]. These protein kinases exhibited mitogen-activated protein kinase (MAPK) or $\mathrm{Ca}^{2+}$-dependent protein kinase (CDPK) properties [22-24]. However, while the list of examples showing the involvement of protein kinases in mediating NO signalling in plants is increasing, only few of them have been firmly identified. This includes the tobacco MAPK salicylic acid-induced protein kinase (SIPK) [23, $25]$ and the alfalfa $\mathrm{p} 34^{\mathrm{cdc} 2}$ cyclin-dependent protein kinase [26].

Besides MAPK and CDPK, we recently investigated the possibility that NO also contributes to the activation of protein kinases belonging to the sucrose nonfermenting 1 (SNF1)-related protein kinase 2 (SnRK2). Plant SnRKs includes three subfamilies (SnRK1, SnRK2 and SnRK3), the SnRK2 and SnRK3 subfamilies appearing to be specific to plants [27- 29]. The SnRK2 protein kinases have been described as key components of water stress and ABA signalling and were shown to contribute to the adaptive responses to drought tolerance [30-34]. Work focused on several SnRK2 members suggested that activity of these protein kinases is regulated by phosphorylation [35-37]. Accordingly, Burza et al. [38] provided evidence that in tobacco bright-yellow 2 (BY-2) cells exposed to salt, the SnRK2 protein kinase NtOSAK (Nicotiana tabacum Osmotic Stress-Activated protein Kinase) is reversibly activated via the phosphorylation on two Ser residues (Ser-154 and Ser-158) located in the kinase activation loop. We also demonstrated that the exposure of Nicotiana plumbaginifolia cell suspensions to the NO donor diethylamine-NONOate (DEA/NO) let to rapid and transient activation of NtOSAK [21]. The NO-induced activation of NtOSAK appeared to be $\mathrm{Ca}^{2+}$-independent [25, 39]. Further supporting a key role for NO in the regulation of NtOSAK, we showed that $\mathrm{NO}$, endogenously produced in N. plumbaginifolia cell suspensions exposed to a sorbitol-induced hyper-osmotic stress, is required for the full 
activation of this SnRK2 protein kinase [21]. Taken together, these results designed SnRK2 protein kinases as NO signalling components.

In animals, NO modulates the activity of different classes of protein kinases including MAPKs, protein kinase C, Janus kinases and the tyrosine kinase Src, by direct chemical modifications of the kinases themselves or by modulation of upstream factors such as small GTP-binding proteins or phosphatases [40-46]. Direct chemical modifications include Snitrosylation and tyrosine nitration [4]. In plants, the process by which NO regulates the activity of protein kinases remains enigmatic. In this study, using BY-2 cell suspensions, we attempted to provide a first insight into the mechanisms underlying this regulation by performing a detailed analysis of NtOSAK posttranslational modifications mediated by NO endogenously produced in response to salt treatment or exogenously released by the NO donor DEA/NO. Our results have shown that in response to NO, NtOSAK is not regulated by S-nitrosylation but via the phosphorylation of two residues located within the kinase activation loop, one being identified as Ser-158. Furthermore, we have identified a cellular partner of NtOSAK, the glycolytic enzyme GAPDH, and provided evidence that in BY-2 cells exposed to salt GAPDH undergoes S-nitrosylation but is not phosphorylated by NtOSAK. Functional analysis further indicated that GAPDH S-nitrosylation did not affect NtOSAK activation nor the complex formation between both enzymes. 


\section{EXPERIMENTAL}

\section{Cell culture and treatments}

BY-2 tobacco cells were cultured as described previously [38]. The cells were treated with $\mathrm{NaCl}(250 \mathrm{mM})$, carboxy PTIO $(500 \mu \mathrm{M})$ or DEA/NO $(50 \mu \mathrm{M})$ for indicated time, harvested by filtration, quickly frozen in liquid nitrogen, and stored at $-80^{\circ} \mathrm{C}$ until analyzed. DEA/NO was prepared as described previously [21].

\section{Immunoblotting}

Western blot analysis was performed according to a standard procedure as described by Burza et al. [38]. Anti-NtOSAK specific polyclonal antibody raised against the C-terminal peptide (KQVQQAHESGEVRLT) of the protein kinase, anti-Ser-158(P) phospho-specific polyclonal antibody raised against the phosphopeptide ${ }^{157} \mathrm{KpSTVGT}$ phosphorylated on residue Ser-158 and anti-GAPDH specific polyclonal antibodies raised against the peptide CYDDIKAAIKEESEG of glyceraldehyde-3-phosphate dehydrogenase were obtained from Biogenes (Berlin, Germany). Proteins from crude extracts were separated on $10 \%$ SDSpolyacrylamide gels and transferred to nitrocellulose by electroblotting using transfer buffer TB (25 mM Tris base, $192 \mathrm{mM}$ glycine) overnight at $15 \mathrm{~V}$. The membrane was blocked over night at $4^{\circ} \mathrm{C}$ temperature in TBST $(10 \mathrm{mM}$ Tris/ $\mathrm{HCl}, \mathrm{pH} 7.5,100 \mathrm{mM} \mathrm{NaCl}, 0.1 \%$ Tween 20$)$ buffer containing $2 \% \mathrm{BSA}$, and then incubated for $1 \mathrm{~h}$ in TBST with the primary antibodies at a dilution 1:1000. In the case of blots probed with the anti-Ser-158(P) antibodies, in order to block nonspecific binding, the membranes were incubated with 5\% BSA and 5\% milk in TBST buffer overnight at room temperature, and then for $2 \mathrm{~h}$ in the same solution with the antibodies at a 1:500 dilution at room temperature and then overnight at $4^{\circ} \mathrm{C}$. After removing unbound antibodies by extensive washing ( 5 times, $5 \mathrm{~min}$ ) with TBST buffer, the blots were incubated $1 \mathrm{~h}$ with alkaline phosphatase-conjugated secondary antibodies (anti-rabbit from Sigma) at a 1:5000 dilution, or with peroxidase-conjugated secondary antibodies (BioRad, USA, 1:50000). After washing (5 times, 5 min) with TBST buffer, immunoreactive proteins were visualized using BCIP/NBT Color Development Substrate (Promega, USA) or Lumiglo Reagent (Cell Signaling Technology, USA) respectively.

\section{Immunoprecipitation}

Immunoprecipitation was performed as described previously [39] with some minor changes. Proteins from BY-2 crude extracts $(4 \mathrm{mg})$ were incubated with anti-NtOSAK antibody $(120 \mu \mathrm{g})$ in immunoprecipitation buffer $(20 \mathrm{mM}$ Tris, $\mathrm{pH} 7.5,2 \mathrm{mM}$ EDTA, $2 \mathrm{mM}$ EGTA, $50 \mathrm{mM} \beta$-glycerophosphate, $100 \mu \mathrm{M} \mathrm{Na} \mathrm{VO}_{4}, 2 \mathrm{mM}$ DTT, $500 \mu \mathrm{M}$ PMSF, $1 \mu \mathrm{M}$ pepstatin, $1 \mu \mathrm{M}$ leupeptin, $1 \mu \mathrm{M}$ aprotinin, $1 \%$ Triton $\mathrm{X}-100,150 \mathrm{mM} \mathrm{NaCl}$ ) at $4^{\circ} \mathrm{C}$ for $4 \mathrm{~h}$ on a rocker. Approximately $50 \mu \mathrm{L}$ of packed volume of protein A-agarose (Santa Cruz Biotechnology, Santa Cruz, CA) was added, and the incubation was continued for another $2 \mathrm{~h}$. Agarose bead-protein complexes were pelleted by brief centrifugation and washed three times with immunoprecipitation buffer and two times with the following buffer: $20 \mathrm{mM}$ Tris, $\mathrm{pH}$ 7.5, $2 \mathrm{mM}$ EDTA, $2 \mathrm{mM}$ EGTA, $50 \mathrm{mM} \beta$-glycerophosphate, $100 \mu \mathrm{M} \mathrm{Na} \mathrm{VO}_{4}, 2 \mathrm{mM}$ DTT, $500 \mu \mathrm{M}$ PMSF, $1 \mu \mathrm{M}$ pepstatin, $1 \mu \mathrm{M}$ leupeptin, $1 \mu \mathrm{M}$ aprotinin. After washing, the immunocomplexes were divided into two pools in a ratio of 1:10. The smaller portion was used directly for immunocomplex kinase activity assay whereas the major part was used for determination of phosphorylation sites by mass spectrometry. In parallel, cell extracts were analyzed by immunoblotting with anti-Ser-158(P) antibodies. 


\section{Immunocomplex kinase activity assay}

Fifty microliters of sample buffer was added to the pelleted agarose bead-protein complex after immunoprecipitation and the sample was heated at $95^{\circ} \mathrm{C}$ for $3 \mathrm{~min}$. After brief centrifugation, supernatant was analyzed by in-gel kinase activity assay.

\section{In-gel kinase activity assays}

In-gel kinase activity assays were performed according to [47]. Protein samples were electrophoresed in $10 \%$ SDS-polyacrylamide gels with $0.5 \mathrm{mg} / \mathrm{mL}$ of myelin basic protein (MBP) embedded in the separating gel as a substrate for the kinase. After electrophoresis, SDS was removed by washing the gel with washing buffer $(25 \mathrm{mM}$ Tris/HCl, pH 7.5, $5 \mathrm{mM}$ $\mathrm{NaF}, 0.5 \mathrm{mg} / \mathrm{mL}$ BSA, $0.1 \%$ Triton X-100 [v/v], $0.5 \mathrm{mM}$ DTT, $0.1 \mathrm{Na}_{3} \mathrm{VO}_{4}$ ) three times each for $30 \mathrm{~min}$ at room temperature. Next, proteins were renaturated overnight in renaturating buffer (25 mM Tris/HCl, pH 7.5, $5 \mathrm{mM} \mathrm{NaF}, 0.1 \%$ Triton X-100, $1 \mathrm{mM} \mathrm{DTT}, 0.1 \mathrm{Na}_{3} \mathrm{VO}_{4}$ ) at $4^{\circ} \mathrm{C}$ with three changes of buffer. The gel was then incubated for $1.5 \mathrm{~h}$ at room temperature in $10 \mathrm{~mL}$ reaction buffer (10 mM Tris/ $\mathrm{HCl}$, pH 7.5, $2 \mathrm{mM}$ DTT, $0.1 \mathrm{mM}$ EGTA, $15 \mathrm{mM} \mathrm{MgCl}$, $20 \mu \mathrm{M}$ ATP, supplemented with $50 \mu \mathrm{Ci}$ of $\left.\left[\gamma^{32} \mathrm{P}\right] \mathrm{ATP}\right)$. Unincorporated $\left[\gamma^{32} \mathrm{P}\right] \mathrm{ATP}$ was removed by extensive washing of the gels in $5 \%$ trichloroacetic acid with $1 \%$ sodium phosphate. Finally, the gels were stained with Coomassie Brilliant Blue R 250, dried, and exposed to X-ray film.

\section{Staining of NtOSAK with Pro-Q Diamond}

Staining was performed as described elsewhere [38].

\section{Mass spectrometry}

Protein samples were analyzed by liquid chromatography - electrospray ionization mass spectrometry with collisional fragmentation (LC-ESI-MS-MS/MS) as described previously [38].

\section{Biotin-switch assay}

Biotin-switch technique was performed according to a procedure described by Sell et al. [48] with some minor changes. After treatment, cells $(0.25 \mathrm{~g})$ were harvested by filtration, frozen in liquid nitrogen, and ground in a mortar. Samples were mixed with $800 \mu \mathrm{L}$ of HEN buffer (25 mM HEPES-NaOH, pH 7.7, 1 mM EDTA, $0.1 \mathrm{mM}$ neucuproine, 2 mM PMSF, 10 $\mu \mathrm{M}$ antipaine, $10 \mu \mathrm{M}$ leupeptine) containing $0.5 \%$ CHAPS and freshly prepared methyl methanethiosulfonate (MMTS, 2M in dimethylformamide (DMF)) added to a final concentration of $5 \mathrm{mM}$. The obtained mixture was centrifuged at $14000 \mathrm{rpm}$ for $20 \mathrm{~min}$ and the corresponding proteins were quantified. Five mg of the proteins was adjusted to $0.8 \mu \mathrm{g} / \mu \mathrm{L}$ HEN buffer and followed by addition of freshly prepared MMTS (2M in DMF) and SDS $(25 \% \mathrm{v} / \mathrm{v})$ to final concentrations of $20 \mathrm{mM}$ and $2.5 \%$, respectively. Following frequent vortexing at $50^{\circ} \mathrm{C}$ for $20 \mathrm{~min}$, proteins were precipitated with 3 vol. acetone at $-20^{\circ} \mathrm{C}$ for 20 min. The proteins were recovered by centrifugation at $3700 \mathrm{rpm}$ for $12 \mathrm{~min}$, followed by gentle rinsing of the pellet 4 times with $1 \mathrm{ml}$ of acetone. The pellets were then suspended in $10 \mu \mathrm{L}$ HEN buffer containing 1\% SDS (HENS) per $100 \mu \mathrm{g}$ starting material of proteins. The samples were divided into two equal pools and were mixed with $1 \mathrm{mM} \mathrm{N}$-[6- 
(biotinamido)hexyl]-3'-(2'-pyridyldithio)propionamide (biotin-HPDP, Thermo Scentific, USA, dissolved in DMF) and $1 \mathrm{mM}$ ascorbate in HEN buffer. For the control samples, appropriate volumes of DMF and ascorbate were added. Labeling reactions were performed in the dark at room temperature for $1 \mathrm{~h}$. Next, the labeling reaction was acetone-precipitated overnight at $-20{ }^{\circ} \mathrm{C}$. The washed pellet was resuspended in $240 \mu \mathrm{L}$ HENS buffer, followed by addition of $750 \mu \mathrm{l}$ neutralization buffer (20 mM HEPES, $100 \mathrm{mM} \mathrm{NaCl}, 1 \mathrm{mM}$ EDTA, $0.5 \%$ Triton-X 100, pH 7.7). This material was incubated for $1.5 \mathrm{~h}$ with $150 \mu 1$ of $50 \%$ neutravidinagarose slurry (previously equilibrated in neutralization buffer). The beads were washed with $4 \times 750 \mu \mathrm{L}$ of wash buffer (neutralization buffer supplemented with $500 \mathrm{mM} \mathrm{NaCl}$ ). The beads were eluted with $70-90 \mu \mathrm{L}$ of $2 x$ Laemmli buffer with $100 \mathrm{mM}$ DTT. The eluted mixture was then analyzed by SDS-PAGE, followed by immunoblotting with anti-NtOSAK (1:1000) or anti-GAPDH (1:1000) antibodies.

\section{Measurement of GAPDH activity}

The activity of GAPDH was determined according to Lindermayr et al. [10] with slight modifications. Crude extracts of BY-2 cell suspension cultures (300 mg protein in 50 $\mathrm{mM}$ Tris- $\mathrm{HCl}, \mathrm{pH}$ 7.5) were incubated with $4 \mathrm{mM}$ arsenate and $100 \mu \mathrm{g} / \mathrm{mL} 3-$ phosphoglycerinaldehyde and were adjusted to $1900 \mu \mathrm{L}$ with $50 \mathrm{mM}$ Tris-Cl, $\mathrm{pH}$ 7.5. The reaction was performed at $30^{\circ} \mathrm{C}$ and initiated by adding $100 \mu \mathrm{L}$ of $100 \mathrm{mM} \mathrm{NAD}^{+}$. The reduction of $\mathrm{NAD}^{+}$to $\mathrm{NADH}$ was monitored by spectrophotometry at $340 \mathrm{~nm}$. For in vitro inhibition assays, protein extracts were incubated before initiation of the reaction with different concentrations of DEA/NO at room temperature for $2 \mathrm{~min}$.

\section{Cloning of cDNAs encoding NtGAPCa and NtGAPCb}

cDNAs encoding NtGAPCa and NtGAPCb were obtained by reverse transcription (RT)- PCR with total RNA isolated from 3 week old Nicotiana tabacum (LA Burley 21 line) plants. RNA was extracted using Triazol Reagent (Invitrogen) according the manufacturer's instruction. First-strand cDNA was synthesized using $5 \mu \mathrm{g}$ of total RNA as template with the Enhanced Avian HS RT-PCR Kit (Sigma Aldrich, Irvine, UK). The cDNA was used for PCR amplification of NtGAPCa and NtGAPCb with primers pairs (listed in supplemental data 5) designed based on nucleotide sequences available in data bases. PCR products were cloned into pCR II-TOPO vector (Invitrogen) and verified by DNA sequencing.

\section{Expression of Recombinant Proteins in Escherichia coli}

Expression and purification of GST-NtOSAK was performed as previously described [38]. Full length cDNAs encoding Nicotiana tobacum cytosolic GAPDHs (NtGAPCa and $\mathrm{NtGAPCb}$ ) were PCR amplified using the appropriate primers listed in supplemental data 5 and EcoRI/SalI fragments of NtGAPCa and EcoRI/XhoI of NtGAPCb were cloned into the expression vector $\mathrm{pET}-28 \mathrm{~A}$ (Novagen).

All PCR reactions were performed using a high-fidelity $P f u$ DNA polymerase (Stratagene, La Jolla, CA) and verified by sequencing. Recombinant proteins were expressed overnight in E.coli BL21-DE3 at $18^{\circ} \mathrm{C}$ and purified using glutathione-agarose beads (Sigma Aldrich, Irvine, UK) as previously described [38] or Ni-NTA agarose beads (Qiagen, Germany) according to the manufacturer's instructions.

\section{In Vitro Binding Assay}


Purified recombinant NtOSAK ( $5 \mu \mathrm{g}$ ) without GST-tag (the GST epitope was cleaved off with thrombin) was mixed with similar amount of $\mathrm{His}_{6}$-NpGAPC1 or NpGAPC2 attached to Ni-NTA-Agarose beads (Qiagen, Germany) or as a control to Ni-NTA-Agarose beads in binding buffer $(50 \mathrm{mM}$ Tris-HCl, $\mathrm{pH} 8.0,300 \mathrm{mM} \mathrm{NaCl}, 10 \mathrm{mM}$ imidazol, and $0.1 \%$ Triton $\mathrm{X}-100$ ). After gentle rotation (over night at $4^{\circ} \mathrm{C}$ ) the beads were centrifuged and washed six times with the binding buffer. Proteins attached to the resin were analyzed by SDS-PAGE and then by Western blotting using anti-NtOSAK antibodies.

\section{Protoplast Transient Expression Assay and Bimolecular Fluorescence Complementation}

Protoplasts were isolated and transformed via PEG treatment according to the protocol of He and colleagues [49] with minor modifications.

After transformation Arabidopsis thaliana T87 protoplasts were suspended in WI incubation solution (0.5 M mannitol, $4 \mathrm{mM}$ MES (pH 5.7), $20 \mathrm{mM} \mathrm{KCl}$ ) and incubated at $25^{\circ} \mathrm{C}$ in the dark for two days.

cDNAs encoding NtOSAK, NtGAPCa, NtGAPCb, NtGAPCa(Cys157Ser,Cys161Ser) and NtGAPCb(Cys154Ser,Cys158Ser) were PCR amplified using $P f u$ DNA polymerase (primers listed in supplemental data 5), cloned into pCR II- TOPO (Invitrogen) and verified by DNA sequencing. For analysis of effect of NtGAPCs (wild type and mutated forms) on NtOSAK activity the XhoI/EcoRI fragment of cDNA encoding NtOSAK and XhoI/BamHI fragments of cDNAs encoding NtGAPCa, NtGAPCb, NtGAPCa(Cys157Ser,Cys161Ser) or $\mathrm{NtGAPCb}$ (Cys154Ser,Cys158Ser) were inserted into the pSAT6-EGFP-C1. For bimolecular fluorescence complementation (BiFC) the cDNA encoding NtOSAK was inserted into pSAT4-nEYFP-C1 and the cDNA fragments for NtGAPCs into pSAT4-cEYFP-C1-B. The vectors were provided by T. Tzfira (University of Michigan, Ann Arbor, MI, USA).

In each transformation about $2 \times 10^{5}$ protoplasts were transfected with about $40 \mu \mathrm{g}$ of plasmid DNA; for BiFC experiments the plasmids were mixed in a $1: 1(\mathrm{w} / \mathrm{w})$ ratio. The transfected protoplasts after incubation in dark for two days were subjected to $250 \mathrm{mM} \mathrm{NaCl}$ treatment. In control experiments, water instead of $\mathrm{NaCl}$ was added to the transfected protoplasts. Protoplasts were carefully placed on slides with home-made chambers preventing damage and drying. Fluorescent images was visualized with the Nikon EZ-C1 laser scanning microscope, equipped with a 60x (NA 1.4) PlanApo oil-immersion objective mounted on an inverted epifluorescence microscope TE 2000E. The fluorescence of EYFP was excited with blue light at $488 \mathrm{~nm}$ emitted by a $40 \mathrm{~mW}$ argon-ion laser (Melles Griot). EYFP fluorescence was detected with a 535/30 nm band-pass filter and rendered in false green. Nuclei were stained with $0.3 \mathrm{mM}$ Hoechst 33342 (H3570, Invitrogen) and excited with the $408 \mathrm{~nm}$ line from an MOD diode laser (Melles Griot). Hoechst fluorescence was detected with a 450/35 $\mathrm{nm}$ band-pass filter and rendered in false blue. Fluorescent images are single optical sections made with the standard EZ-C1 Nikon software. Brightness and contrast were adjusted with Adobe Photoshop 6.0 program.

\section{Site-directed mutagenesis}

pSAT6-EGFP-NtGAPCa and pSAT6-EGFP-NtGAPCb constructs were used as a template for site-directed mutagenesis with the Quick Change II site-directed mutagenesis kit (Stratagene, La Jolla, CA). The primers used for substitution of Cys157 and Cys161 in NtGAPCa and Cys154 and Cys158 in NtGAPCb are listed in supplemental data 5. The obtained constructs were sequenced to verify the introduced mutations. 


\section{RESULTS}

\section{NO contributes to NaCl-induced NtOSAK activation}

Protein kinase activities were assessed by in-gel kinase assays using MBP as a substrate. Exposure of BY-2 cells to $250 \mathrm{mM} \mathrm{NaCl}$ resulted in the rapid activation of two protein kinases with apparent molecular mass of 47 and $42 \mathrm{kDa}$ previously identified as SIPK and NtOSAK, respectively (Figure 1; [50]). To investigate the involvement of NO in mediating NaCl-induced SIPK and NtOSAK activation, cPTIO, a NO scavenger, was used. This compound has been shown to suppress the fast production of NO triggered by salt both in tobacco cell suspensions and plant tissues [51]. Pre-treatment of BY-2 cells with cPTIO affected the salt-induced activation of SIPK and NtOSAK: SIPK activation was almost completely suppressed whereas NtOSAK activity was reduced by about $50 \%$. As recently reported $[21,25]$, the ability of $\mathrm{NO}$ to promote NtOSAK activation was confirmed by the demonstration that treatment of BY-2 cells with $50 \mu \mathrm{M}$ of the NO donor DEA-NONOate (DEA/NO) promotes its transient activation within 30 min (Figure 2A). In contrast, SIPK activation by DEA/NO was detected only at $\mathrm{mM}$ concentrations of DEA/NO (data not shown, [25]). Taken together, these data indicate that the activation of NtOSAK triggered by salt depends, at least partially, on NO production. This result fits well with our previous study [21] showing that NO produced in response to sorbitol-induced hyper-osmotic stress acts upstream of NtOSAK.

\section{NO regulates NtOSAK by phosphorylation on residues Ser-154 and Ser-158 but not via S-nitrosylation}

To decipher the mechanisms underlying NtOSAK activation by NO, we analysed its phosphorylation state in tobacco cells exposed to $50 \mu \mathrm{M}$ of DEA/NO for $30 \mathrm{~min}$. For this purpose, protein extracted from DEA/NO or salt-treated cells were immunoprecipitated with a specific anti-NtOSAK polyclonal antibody and the resulting immunocomplexes were analysed by in gel kinase assay (Figure 2A) and stained with the Pro-Q-diamond stain (Figure 2B) which recognizes phosphorylated Ser, Tyr and Thr residues. As shown in figure 2B, NtOSAK displays phosphorylation in BY-2 cells exposed to salt accordingly to [38], but also in response to DEA/NO. The phosphorylation of NtOSAK was well correlated with its protein kinase activity (Figure 2A).

We next mapped the NtOSAK amino acid residues undergoing phosphorylation in tobacco cells exposed to DEA/NO. A particular attention was paid to residues Ser-154 and Ser-158 as active NtOSAK, isolated from NaCl-treated BY-2 cells, was shown to be phosphorylated on those residues [38]. First, protein extracts from DEA/NO or NaCl-treated BY-2 cells were subjected to western blot analysis and probed with the phospho-specific antibodies anti-Ser(P)-158. These antibodies, raised against the phosphorylated peptide ${ }^{157} \mathrm{KpSTVGT}$, specifically react with NtOSAK phosphorylated on the residue Ser-158 [38]. As expected, immunostaining revealed one band in the protein extracts corresponding to phosphorylated NtOSAK present in NaCl-treated cells (Figure 2C). Of interest, the antibodies recognized the phospho-peptide also in the protein extracts from cells exposed to DEA/NO for $30 \mathrm{~min}$, indicating that NtOSAK is phosphorylated on residue Ser-158 in response to NO. Second, in order to check whether NO promotes the phosphorylation of residue Ser-154, NtOSAK was immunoprecipitated from BY-2 cells untreated or treated with DEA/NO for 30 min according to the procedure described by Burza et al. [38] and subjected to SDS-PAGE. Then, the protein was excised from the gel and the corresponding tryptic fragments analysed by LC-MS-MS/MS. In the samples corresponding to DEA/NO-treated cells, the mass 
spectrometry analysis revealed the presence of two peptides (residues 149 to 157; residues 158 to 173 , Table 1) containing Ser-154 and Ser-158, respectively, and showing a $\mathrm{m} / \mathrm{z}$ value increased by 40 as compared to the $\mathrm{m} / \mathrm{z}$ values measured in the control samples. This difference in the $\mathrm{m} / \mathrm{z}$ value, expected for doubly charged phosphorylated species, corresponds to a difference of $80 \mathrm{Da}$ and highlights the presence of a phosphorylated residue in both peptides. Therefore, based on the immunoblot assay (figure 2C) and Burza et al. [38] finding showing that NtOSAK is phosphorylated on Ser-158 and Ser-154 in response to salt treatment, our mass spectrometry result strongly suggest that NO up-regulates NtOSAK activity by promoting the phosphorylation on both Ser residues.

We also considered the possibility that NO might regulate NtOSAK through Snitrosylation. To verify this assumption, NtOSAK putative $S$-nitrosylation was surveyed by the biotin switch assay [52] after treatment of BY-2 cells with the NO donor DEA-NO or $\mathrm{NaCl}$ for various time (up to $1 \mathrm{~h}$ ). In a first step, protein extracts were treated with methyl methanethiosulfonate (MMTS) in order to chemically block all free thiol groups without modifying nitrosothiols or disulfides. In a second step, nitrosothiols, but not disulfides, were reduced to free thiol groups by ascorbate. This step was followed by the biotinylation of the newly formed free thiols by $N$-[6-(biotinamido)hexyl]-3'-(2'-pyridyldithio)propionamide (biotin-HPDP). Next, the biotinylated proteins were concentrated by affinity purification with neutravidin-agarose, eluted under reducing conditions using a DTT-enriched buffer and then subjected to western blot analysis using specific anti-NtOSAK polyclonal antibody. As shown in figure 3, immunostaining did not reveal the presence of NtOSAK in the samples corresponding to biotinylated proteins. In contrast, NtOSAK was clearly detected in the samples containing proteins that did not bind to neutravidin, that is which were not biotinylated during the biotin switch assay. The presence of NtOSAK in the samples corresponding to non-biotinylated proteins suggested that NtOSAK is not regulated by Snitrosylation in response to salt or NO released by DEA/NO.

\section{GAPDH is present in immunocomplex with NtOSAK and undergoes S-nitrosylation under salt treatment}

To further explore NtOSAK regulation in the salt signalling pathway, a search for proteins which interact with NtOSAK was performed. For this purpose, we undertook the identification of proteins co-immunoprecipitating with NtOSAK in extracts prepared from BY-2 cells subjected to $250 \mathrm{mM} \mathrm{NaCl}$ for $5 \mathrm{~min}$. Proteins pulled down together with NtOSAK in the immunocomplex or preimmune serum (negative control) were separated by SDS-PAGE and the coomassie-stained protein bands were excised from the gel (supplemental data 1) . After in-gel digestion with trypsin, the corresponding peptides were analyzed by ESIMS-MS/MS and identified using the MASCOT search engine. The list of proteins selectively co-immunoprecipitated with NtOSAK, but not with the preimmune serum, as well as their functional classification, is shown in Table 2. These proteins are related to N/C metabolism, cellular architecture, protein synthesis and degradation and ATP metabolism.

Interestingly, one of the NtOSAK's potential partners showing the highest score corresponds to the glycolytic enzyme GAPDH. In animals, NO was shown to elicit Snitrosylation of GAPDH under several physiological context, including apoptosis [53,54]. In A. thaliana, Lindermayr et al. [10] demonstrated that GAPDH is S-nitrosylated in vitro by artificially released $\mathrm{NO}$, this process leading to a reversible inhibition of the enzyme activity. Based on these data, we monitored the influence of NO on GAPDH by analyzing its Snitrosylation profile in BY2 cells exposed to salt or DEA/NO for up to $1 \mathrm{~h}$. For this purpose, proteins extracted at different time points during both treatments were subjected to the biotin 
switch assay. The resulting biotinylated proteins were purified by affinity chromatography using neutravidin-agarose and then subjected to western blot analysis using specific antiGAPDH polyclonal antibody. As a negative control, the same procedure was performed without adding biotin-HPDP. The immunoblots presented on figure 4 show the presence of a band only in the samples in which biotin-HPDP was added during the biotin switch assay. Therefore, the detection of the immunoreactive bands in those samples did not reflect a constitutive and/or inducible endogenous biotinylation of GAPDH in response to salt or DEA/NO treatment but highlighted the S-nitrosylation of the enzyme. More precisely, Snitrosylated GAPDH was already detected at zero time point, suggesting that the enzyme is constitutively S-nitrosylated in our culture condition. In response to DEA/NO, the level of Snitrosylation increased after $30 \mathrm{~min}$, a time at which NtOSAK showed its highest activity in NO-treated cells (Figure 2A). In cells challenged by salt, the increase or GAPDH Snitrosylation was maximal at 5-15 min and returned to the basal level within $30 \mathrm{~min}$ (see also supplemental data 2 for quantification). Here too, the increase of GAPDH S-nitrosylation level was well correlated with NtOSAK kinetic of activity (Figure 1). Taken together, these data indicate that in BY-2 cells exposed to salt, GAPDH is present in immunocomplex with NtOSAK and the induction of NtOSAK protein kinase activity and GAPDH S-nitrosylation occur in the same lapse of time. However, it should be specified that only a small proportion of GAPDH appeared to be regulated by S-nitrosylation in response to salt as most of the enzyme was clearly detected in the non S-nitrosylated fraction (supplemental data 3).

\section{GAPDH activity is not impaired in BY2 cells exposed to salt or DEA/NO}

As stated above, it was previously reported that the exposure of crude extracts of $A$. thaliana cell cultures to NO donors leads to the inhibition of GAPDH activity through direct S-nitrosylation [10]. Because GAPDH was found to be transiently S-nitrosylated in BY2 cells exposed to salt or DEA/NO (Figure 4), we investigated whether these treatments could affect the activity of the enzyme. Therefore, BY2 cell suspensions were exposed to $\mathrm{NaCl}$ or DEA/NO for various time, and total GAPDH activity was determined. As shown Figure 5A, treatment of cells suspension with salt or DEA/NO did not affect the total GAPDH activity. To complete this data, we next analysed GAPDH activity in BY2 cells crude extracts exposed to DEA/NO at room temperature. Similarly to Lindermayr et al. [10] study, under this in vitro condition, the NO donor reduced the GAPDH activity by $25 \%$ and $85 \%$ when used at $50 \mu \mathrm{M}$ or $500 \mu \mathrm{M}$, respectively (Figure 5B). In sum, these results indicate that whereas an inhibition of GAPDH activity by $\mathrm{NO}$ occurred in vitro, the activity of the enzyme was not impaired in vivo following the exposure of BY2 cells to salt or DEA/NO. This suggests that the Snitrosylation of GAPDH observed in vivo (Figure 4) had a negligible effect on the total GAPDH activity. This result seems plausible as only a small proportion of GAPDH undergoes S-nitrosylation under these conditions (Figure 4 and supplemental data 3).

\section{GAPDH interacts directly with NtOSAK}

In order to establish whether GAPDH interacts directly or indirectly with NtOSAK, in vitro pull down assay was applied. Arabidopsis thaliana genome encodes two cytosolic GAPDHs, GAPC1 (At3g04120) and GAPC2 (At1g13446). In NCBI nucleotide data base, two cDNA sequences for Nicotiana tabacum cytosolic GAPDHs were deposited (accession numbers M14419, partial cDNA sequence, and AJ133422). We have cloned cDNAs encoding these GAPDHs (NtGAPCa and NtGAPCb) by RT-PCR using total RNA isolated from tobacco seedlings as a template and appropriate primers designed based on sequences available in nucleotide and EST data bases. The sequences of the cDNA we cloned did not 
completely fit with those of M14419 and AJ133422 deposited in NCBI data base. The sequence identity between NtGAPCa and M14419, and between NtGAPCb and AJ133422 were about 99\%, respectively. Analogous discrepancies were also observed for Arabidopsis thaliana GAPCs [9]. Most probably, these variations are due to ecotype-specific GAPDHs in plants.

In order to produce the tobacco GAPDH proteins for a pull down assay, the cloned cDNAs were introduced into bacterial expression vector pET-28A and recombinant proteins His $_{6}-\mathrm{NtGAPCa}$ and $\mathrm{His}_{6}-\mathrm{NtGAPCb}$ were produced in E.coli. NtOSAK was expressed in E.coli as a fusion protein with a GST-tag, purified on glutathione-Sepharose beads, and the GST epitope was cleaved off with thrombin. The purified NtOSAK was incubated with $\mathrm{His}_{6}$ $\mathrm{NtGAPCa}$ or $\mathrm{His}_{6}-\mathrm{NtGAPCb}$ attached to $\mathrm{Ni}^{2+}$ NTA-Agarose or with $\mathrm{Ni}^{2+}$ NTA-Agarose beads, as a control. After incubation followed by extensive washing of the beads, the presence of NtOSAK bound to $\mathrm{His}_{6}-\mathrm{NtGAPCa}$ or $\mathrm{His}_{6}-\mathrm{NtGAPCb}$ or to free $\mathrm{Ni}^{2+}$ NTA-Agarose (control) was analyzed by SDS-PAGE and then by Western blotting using anti-NtOSAK antibodies (Figure 6). The results revealed that NtOSAK interacts directly with both NtGAPCs.

\section{GAPDH interacts with NtOSAK in planta}

To study the interaction between NtOSAK and GAPDH in plant cells we applied bimolecular fluorescence complementation (BiFC). Appropriate constructs for transient expression of NtOSAK and NtGAPCa or NtGAPCb fused to complementary non-fluorescent fragments of YFP (described in Experimental section) were introduced into Arabidopsis thaliana (T-87 cells) protoplasts. In first approach, we have tried to transform tobacco BY-2 cells protoplasts for this purpose, however in our hands this transformation was not efficient enough. Therefore, we have chosen Arabidopsis thaliana protoplasts for our studies. Interaction of the protein partners resulted in reconstruction of YFP protein and its fluorescence. For negative controls, each fusion protein was tested in the presence of the other half of YFP alone. We have observed NtOSAK-NtGAPCa and NtOSAK-NtGAPCb complex formation in protoplast not treated and treated with $250 \mathrm{mM} \mathrm{NaCl}$ (Figure 7). In the absence of salt treatment, the NtOSAK-NtGAPCa complex formation occurred mainly in the cytoplasm and sporadically also in the nucleus, while the NtOSAK-NtGAPCb complex was localized more often to the nucleus (besides the cytoplasm), suggesting that both GADPHs may have different function in plant cells. The salt treatment did not change significantly the complexes localization. Moreover, NtGAPCb very often formed aggregates (when expressed in protoplasts with or without NtOSAK). Aggregate formation is a well know feature of GAPDH, which can play a role in oxidative stress-induced cell death [55].

We have also analyzed the impact of NtGAPCa or NtGAPCb S-nitrosylation on their interaction with NtOSAK. It was shown previously that Cys-155 and 159 of Arabidopsis thaliana GAPC1 and GAPC2, corresponding to Cys-157 and 161 or Cys-154 and 158 of tobacco NtGAPCa or NtGAPCb, respectively, undergo glutathionylation and S-nitrosylation [9]. Therefore, we substituted these Cys residues in NtGAPCa and NtGAPCb with Ser residues and used constructs with cDNA encoding NtGAPCa(Cys157Ser,Cys161Ser) or $\mathrm{GAPCb}$ (Cys154Ser,Cys158Ser) and NtOSAK fused to complementary fragments of YFP for/in BIFC analysis. Mutated GAPCs interacted with NtOSAK, however exclusively in the cytoplasm (Figure 7), since NtGAPCa(Cys157Ser,Cys161Ser) and $\mathrm{GAPCb}(\mathrm{Cys} 154 \mathrm{Ser}, \mathrm{Cys} 158 \mathrm{Ser})$ were not found in the nucleus.

In sum, our results indicate that NtOSAK interacts with GAPDH in living plant cells and this interaction is independent of stress application and S-nitrosylation. However, the absence of 
the complexes between NtOSAK and the mutated forms of NtGAPCa and NtGAPCb in the nucleus suggests that the corresponding Cys residues in the native forms of NtGAPCs might play an important role in the cellular localization of the proteins.

\section{NtOSAK does not phosphorylate GAPDH in vitro and in our experimental conditions GAPDH does not influence NtOSAK activity.}

The interaction between NtOSAK and NtGAPCa or NtGAPCb indicates that GAPDH can be a substrate of NtOSAK and/or one of its regulator in plant cells. To determine if tobacco GAPDH could be phosphorylated by NtOSAK, in vitro phosphorylation reaction was performed using purified proteins (NtOSAK and $\mathrm{His}_{6}-\mathrm{NtGAPCa}$ or $\mathrm{His}_{6}-\mathrm{NtGAPCb}$ ) expressed in E.coli. Additionally, as a source of the active kinase we used NtOSAK purified from tobacco BY-2 cells, as it was described in [39]. Phosphorylation reaction was conducted in standard phosphorylation conditions elaborated for this kinase [39]. Our result indicate that GAPDH is not phosphorylated by NtOSAK in vitro (data not shown).

To corroborate the possible role of the S-nitrosylation of GAPDH in NtOSAK activation in response to salinity stress, we expressed EGFP-NtOSAK with EGFP-NtGAPCa or EGFP-GAPCb (wild types and their mutated forms, EGFPNtGAPCa(Cys157Ser,Cys161Ser) or EGFP-GAPCb(Cys154Ser,Cys158Ser) in Arabidopsis thaliana protoplasts. Two days after transformation protoplasts were treated with $250 \mathrm{mM}$ $\mathrm{NaCl}$ and activity of EGFP-NtOSAK expressed in protoplasts together with each of NtGAPCs (not mutated or mutated) or with EGFP (as control) was analyzed. The kinase activity was monitored by in-gel kinase activity assay using MBP as substrate. In our experimental conditions we have not observed any significant changes of NtOSAK activity caused by the presence of NtGAPCs (wild types or mutated forms) in plant protoplasts (supplemental data 4). However, it has to be stressed out that in protoplasts the level of endogenous, native GAPDH, was very high in most experiments, even higher than transiently expressed EGFP-NtGAPCa or EGFP-GAPCb (supplemental data 4). Therefore, the effect of introduced artificially NtGAPCs on NtOSAK activity is extremely difficult to estimate. Additionally, GAPDH exists in oligomeric forms; in analyzed protoplasts most probably the native Arabidopsis thaliana GAPC1 or GAPC2 can form oligomers with expressed EGFPNtGAPCs, and this makes the analysis even more complicated. In our experimental conditions we are simply unable to establish the role of GAPDH and its S-nitrosylation in NtOSAK signaling in response to salinity stress. 


\section{DISCUSSION}

In previous studies, we reported that NO promotes the activation of the SnRK2 protein kinase NtOSAK in tobacco cell suspensions subjected to a hyper-osmotic stress triggered by sorbitol [21]. In the present work, we confirmed the key role of NO in regulating NtOSAK activity in vivo by showing that it also contributes to NtOSAK activation in BY-2 cells exposed to salt stress. The functional relationship between NO and NtOSAK is further strengthened by the demonstration that the protein kinase is transiently activated in response to NO artificially released by the NO donor DEA/NO (this study, [21,25]). The observation that the NO scavenger cPTIO partly, but not completely, suppressed the salt-induced NtOSAK activation suggests that the up-regulation of the protein kinase may occur through both NO-dependent and NO-independent pathway. It is also plausible that the partial inhibition of NtOSAK might be related to the inability of cPTIO to fully scavenge NO produced in response to salt. Supporting this assumption, [51] reported that the scavenging efficiency of cPTIO varies according to the abiotic stress applied to plant cell suspensions. Notably, these authors observed that in tobacco cell suspensions, the addition of $250 \mathrm{mM}$ of $\mathrm{NaCl}$ in the extracellular medium reduced by $40 \%$ the efficiency of CPTIO to scavenge NO released by the NO donor NOC-9. The mechanism underlying this observation remains to be investigated.

Recent studies indicated that the members of SnRK2 subfamily including NtOSAK are activated by phosphorylation $[35,38,50,56]$. Accordingly, we found that the activation of NtOSAK observed in BY-2 cells exposed to DEA/NO is correlated with an increase of its phosphorylation status. Furthermore, mass spectrometry analysis of NtOSAK purified form DEA/NO-treated cells revealed the presence of two phosphopeptides $\left({ }^{149}\right.$ SSLLHSRPK $^{157}$; ${ }^{158}$ STVGTPAYIAPEVLSR ${ }^{173}$ ) containing Ser-154 and Ser-158, respectively. Those residues are localized in the kinase activation loop (residues 143 to 169) and were previously identified as two key phosphorylation sites in active NtOSAK [38]. The NO-induced phosphorylation of residue Ser-158 was further confirmed by its visualization by western blotting with antiSer(P)-158 antibodies. Taken together, these data establish that in response to the NO donor, NtOSAK undergoes phosphorylation on residues Ser-158 and on a second serine residue localized within the peptide ${ }^{149}$ SSLLHSRPK $^{157}$ and which might correspond to Ser-154. Therefore, the mechanisms by which NO activates NtOSAK resembles those observed in response to salt. This finding clearly reinforces the notion that NO is a key mediator of NtOSAK activation.

Beside phosphorylation, we also monitored whether NtOSAK could be regulated by Snitrosylation. In animals, S-nitrosylation has been shown to impact the activity of several protein kinases, including for instance Janus kinases and the apoptosis signalling kinase 1 [54]. It was therefore plausible that the S-nitrosylation of NtOSAK could promote conformational changes favouring its phosphorylation by an upstream kinase. Our finding indicates that in BY-2 cells exposed to salt or DEA/NO, NtOSAK did not undergo Snitrosylation. Accordingly, in preliminary in vitro S-nitrosylation assays, we were not able to find NtOSAK amongst the S-nitrosylated proteins identified from BY-2 cells protein extracts exposed to the S-nitrosylating agent S-nitrosoglutathione (GSNO; data not shown). Therefore, NtOSAK might not be regulated by direct S-nitrosylation of critical Cys-residue(s).

There is a mounting amount of data indicating that SnRKs link metabolism and stress signalling in plants [28]. Studies in rice and A. thaliana showed that ABF (ABA response element Binding Factor) transcription factors as well as proteins related to energy metabolism are targets for SnRK2 protein kinases [57-59]. Accordingly, we found that NtOSAK coimmunoprecipitated with proteins primary involved in N/C metabolisms and ATP synthesis 
and transport. The other interacting proteins include the elongation factor- 1 alpha that binds aminoacyl-tRNAs to the acceptor site of ribosomes during peptide chain elongation [60], the $26 \mathrm{~S}$ proteasome subunit 4-like and proteins related to cytoskeleton. The possibility that elongation factors represent SnRK2 interacting proteins has been previously reported by [59] who identified several phosphorylated targets of the A. thaliana SnRK2.8 protein kinase.

Amongst the NtOSAK-interacting proteins, we preferentially focused our attention on GAPDH. Several arguments supported this choice. First, in animals, besides its glycolytic activity, GAPDH participates in several cellular events including gene transcription, RNA transport and DNA replication [61]. This multifunctional protein has been reported to be inhibited by S-nitrosylation of a conserved catalytic Cys residue, both in vitro and in vivo. Interestingly, [53] reported that in macrophages exposed to endotoxin as well in neurons elicited by glutamate, the S-nitrosylation of GAPDH causes structural changes allowing GAPDH to interact with the E3 ubiquitin ligase Siah1. The complex is then translocated into the nucleus where Siah1 promotes cell death through the ubiquitin-mediated degradation of nuclear target proteins. Second, in A. thaliana, GAPDH from cell culture crude extracts, as well as its recombinant purified cytosolic isoform were shown to be in vitro S-nitrosylated by the NO donors GSNO and sodium nitroprusside $[9,10]$. In those studies, S-nitrosylation let to the inhibition of its enzymatic activity. Finally, in various organisms including plants, GAPDH was identified as direct targets of $\mathrm{H}_{2} \mathrm{O}_{2}$ [62,63]. Mechanistically, $\mathrm{H}_{2} \mathrm{O}_{2}$ triggers the inhibition of GAPDH through the oxidation of the catalytic Cys residue also prone to $\mathrm{S}$ nitrosylation. In yeast, the $\mathrm{H}_{2} \mathrm{O}_{2}$-induced oxidation of GAPDH was shown to promote its interaction with the response regulator Mcs4 which, in turn, activates the Spc1 MAPK cascade [63]. Taken together, these data indicate that GAPDH has roles outside of that of glycolysis and modulates cellular signalling pathways once S-nitrosylated or oxidized on a critical Cys residue.

Based on these studies, we investigated the degree of S-nitrosylation of GAPDH in salt-treated BY-2 and found that it undergoes an increased and transient S-nitrosylation. The kinetics of GAPDH S-nitrosylation in response to salt or DEA/NO was well correlated with the kinetics of NtOSAK activation, suggesting that the physical association between both proteins might have been related to their respective S-nitrosylated and phosphorylated status. However, our studies have not confirmed this hypothesis. The complex formation analysis in planta indicate that the proteins interact with each other before and after stress application, and their interaction does not depend on S-nitrosylation of GAPDH. The increased Snitrosylation of GAPDH cells exposed to salt or DEA/NO was not accompanied by a reduction of the total GAPDH enzymatic activity. This observation resembles the situation encountered in stimulated macrophages in which only a small proportion of GAPDH is Snitrosylated with a negligible effect on overall cellular glycolysis [53,64]. Consistently, after applying the biotin switch assay to proteins extracted from salt and DEA/NO-treated BY-2 cells, GAPDH was also strongly detected in the samples corresponding to proteins that did not bind to neutravidin (suplemental data 2).

In mammals activity of GAPDH can be modulated by phosphorylation [65]. Therefore we have considered that in response to salinity stress GAPDH can be regulated by phosphorylation catalyzed by NtOSAK. However, we were unable to detect phosphorylation of tobacco GAPDH by NtOSAK (in vitro studies). Moreover, our MS data also did not show any phosphorylated peptides of GAPDH isolated from tobacco cells. To establish a possible role of GAPDH in NtOSAK signalling we expressed NtOSAK in Arabidopsis thaliana protoplasts together with tobacco GAPDH and monitored NtOSAK activity after salt stress application. Two different cytosolic GAPDHs were tested, that is wild type and mutated forms in which the Cys residues undergoing S-nitrosylation were substituted with Ser residues. We did not observe any significant differences in the kinase activity due to GAPDH 
over-expression, suggesting that the S-nitrosylation state of GAPDH does not influence NtOSAK activity. These results do not exclude the possibility that interaction with GAPDH and its additional S-nitrosylation in response to salinity can influence NtOSAK substrate specificity and/or interaction with other NtOSAK signalling components.

In conclusion, this study provides the first description of the mechanisms underlying NO-induced activation of protein kinases in a physiological context in plants. The finding that GAPDH associates to NtOSAK and following exposure to salt undergoes an increased Snitrosylation suggests that besides its glycolytic activity, GAPDH might act as a component of a signalling cascade involving phosphorylation-dependent events. Work is ongoing to address these issues. 


\section{ACKNOWLEDGEMENT}

This work was supported by the Conseil Régional de Bourgogne (funding number 079201 CPER O2 S 5527), the Agence Nationale de la Recherche (BLAN07-2_184783), the Ministère des Affaires Etrangères (EGIDE Polonium, grant 11545WG) and the Ministry of Science and Higher Education (grants N N301 2540 and 500/N-COST/2009/0). Izabela Wawer was supported by a fellowship from the the Conseil Régional de Bourgogne (funding number 07 HCP 36) 


\section{FIGURE LEGENDS}

Figure 1. NO contributes to the activation of NtOSAK and SIPK induced in response to salt. cPTIO $(500 \mu \mathrm{M})$ was added to BY-2 cell suspensions 10 min prior to salt $(250 \mathrm{mM} \mathrm{NaCl})$. Aliquots of the culture were taken at the indicated times and analyzed for protein kinase activities by in-gel kinase assay with $\mathrm{MBP}$ as substrate. Results are from one of five representative experiments.

Figure 2. NO induces NtOSAK phosphorylation.

A. DEA/NO triggers NtOSAK activation in BY-2 cell suspensions. Cell suspensions were treated with DEA/NO $(50 \mu \mathrm{M})$ for indicated time or with $\mathrm{NaCl}(250 \mathrm{mM})$ for $5 \mathrm{~min}$ as a positive control. Protein extracts were immunoprecipitated with anti-NtOSAK antibodies. The resulting immunocomplexes were analyzed by in-gel kinase assay with MBP as substrate. Results are from one of five representative experiments.

B. The immunocomplexes obtained in (A) were subjected to SDS-PAGE. Phosphorylation of NtOSAK was determined by ProQ Diamond stain. Results are from one of three representative experiments.

C. Analysis of NtOSAK phosphorylation on residue Ser-158. Crude extracts from BY-2 cells trated with DEA/NO $(50 \mu \mathrm{M})$ for $60 \mathrm{~min}$ or $\mathrm{NaCl}(250 \mu \mathrm{M})$ for $5 \mathrm{~min}$ were subjected to western analysis and probed with anti-Ser(P)-158 antibodies. Results are from one of three representative experiments.

Figure 3. NtOSAK does not undergo S-nitrosylation.

BY-2 cell suspensions were treated with DEA/NO $(50 \mu \mathrm{M})$ or with $\mathrm{NaCl}(250 \mathrm{mM})$ for indicated time. The corresponding crude extracts were subjected to the biotin switch assay. Biotinylated proteins were purified with neutravidin-agarose and eluted under reducing conditions. Biotinylated proteins and non-biotinylated proteins (that is, proteins that did not bound to neutravidin) were analysed by western-blot using anti-NtOSAK antibodies. Results are from one of three representative experiments.

Figure 4. Salt-stress induced GAPDH S-nitrosylation

BY-2 cell suspensions were treated with DEA/NO $(50 \mu \mathrm{M})$ or with $\mathrm{NaCl}(250 \mathrm{mM})$ for indicated time. The corresponding crude extracts were subjected to the biotin switch assay. As a negative control, the biotin switch assay was performed, without adding the sodium ascorbate. Biotinylated proteins were then purified with neutravidin-agarose, eluted under reducing conditions and analyzed by western-blot using anti-GAPDH antibodies. Results are from one of three representative experiments.

Figure 5. GAPDH activity is not inhibited in salt or DEA/NO treated cells

A - In vivo activity. BY-2 cell suspensions were treated with DEA/NO $(50 \mu \mathrm{M})$ for 30 min or with $\mathrm{NaCl}(250 \mathrm{mM})$ for $5 \mathrm{~min}$. Then, GAPDH activity was measured by following the time course of $\mathrm{NAD}^{+}$reduction to NADH by spectrophotometry at $340 \mathrm{~nm}$ (see Material and Method section). Results are from one of three representative experiments.

$\mathrm{B}$ - In vitro activity. Proteins extracted from untreated BY-2 cells were exposed to NO artificially released by DEA/NO $(50$ or $500 \mu \mathrm{M})$ for $2 \mathrm{~min}$ and GAPDH activity was measured as specified in A. Results are from one of three representative experiments.

Figure 6. NtOSAK directly interacts with NtGAPCa and NtGAPCb

In vitro binding assay of $\mathrm{His}_{6}-\mathrm{NtGAPCa}$ and $\mathrm{His}_{6}-\mathrm{NtGAPCb}$ with $\mathrm{NtOSAK}$. 
$\mathrm{Ni}^{2+}$ NTA-Agarose with attached $\mathrm{His}_{6}-\mathrm{NtGAPCa}$ or $\mathrm{His}_{6}-\mathrm{NtGAPCb}$ was incubated with purified NtOSAK produced in E.coli., or as a control NtOSAK was incubated with $\mathrm{Ni}^{2+} \mathrm{NTA}-$ Agarose. In additional controls NtOSAK was not added to $\mathrm{His}_{6}-\mathrm{NtGAPCa}$ or $\mathrm{His}_{6}-\mathrm{NtGAPCb}-$ $\mathrm{Ni}^{2+}$ NTA-Agarose. After washing the presence of NtOSAK attached to the beads was analyzed by Western blotting with anti-NtOSAK antibodies. Data represent one of three independent experiments showing similar results.

Figure 7. NtOSAK interacts with NtGAPCa and NtGAPCb in planta

$\mathrm{NtOSAK}$ interacts with NtGAPCa and NtGAPCb in Arabidopsis thaliana T87 protoplasts, as shown by BIFC. The physicall interaction of NtOSAK and NtGAPCa or NtGAPCb leads to reconstitution of EYFP molecule.

EYFP signal was localised mainly to the cytoplasm in the case of complex formation between NtOSAK and NtGAPCa before (A) and after 1h treatment with $250 \mathrm{NaCl}$ (C). EYFP was localised to the cytoplasm and nucleus in the case of interaction between NtOSAK and $\mathrm{NtGAPCb}$ before (B) and after $1 \mathrm{~h}$ treatment with $250 \mathrm{NaCl}$ (D). Interaction between NtOSAK and GAPCa(Cys157Ser,Cys161Ser) or GAPCb(Cys154Ser,Cys158Ser) in protoplasts not treated ( $\mathrm{E}$ and $\mathrm{F}$, respectively) and treated with $\mathrm{NaCl}(\mathrm{G}$ and $\mathrm{H}$, respectively) gave the BIFC signal restricted only to the cytoplasm. False green colour represents EYFP (BIFC). False blue colour represents stained nuclei (Hoechst). Overlay of the EYFP and Hoechst signals (Merge).

Data represent one of several independent experiments showing similar results. 
Table 1. Mass spectrometric identification of NtOSAK phosphorylation peptides.

\section{Control}

ion score $(\mathrm{m} / \mathrm{z}$, charge $)$ ion score $(\mathrm{m} / \mathrm{z}$, charge $)$

\section{Phosphorylated peptides - sequence}

(149)SSLLHSRPK(157)

(158)STVGTPAYIAPEVLSR(173)

\section{Unphosphorylated peptides - sequence}

$$
\text { (149)SSLLHSRPK(157) }
$$
(158)STVGTPAYIAPEVLSR(173)

$$
42\left(512.79,2^{+}\right)
$$$$
78\left(830.94,2^{+}\right)
$$

$33\left(552.77,2^{+}\right)$

$34\left(870.93,2^{+}\right)$

$40\left(512.79,2^{+}\right)$

$60\left(830.94,2^{+}\right)$

BY-2 cell suspensions were treated with DEA/NO $(50 \mu \mathrm{M})$ for $30 \mathrm{~min}$. Protein extracts were immunoprecipitated with anti-NtOSAK antibodies and separated by SDS-PAGE. Coomassiestained protein bands were excised from the gel and analyzed by LS-MS-MS/MS after in-gel digestion with trypsin. Protein sequence database search was carried out by MASCOT (MatrixScience.com). MS/MS fragmentation ion scores (ion scores) indicates the presence or absence of a phosphorylated and unphosphorylated form of the peptide containing Ser-154 and Ser-158 in NtOSAK. For each peptide signal its $\mathrm{m} / \mathrm{z}$ and charge is given.

- : lack of the phosphorylated form of the peptide.

Results are from one of three representative experiments. 
Table 2. Identification of proteins co-immunoprecipitating with NtOSAK in BY-2 cells exposed to salt.

\begin{tabular}{llccc}
\hline $\begin{array}{c}\text { Accession } \\
\text { no. }\end{array}$ & \multicolumn{1}{c}{ Name } & $\begin{array}{c}\text { Protein } \\
\text { score }\end{array}$ & $\begin{array}{c}\text { Queries } \\
\text { matched }\end{array}$ & $\begin{array}{c}\text { Band } \\
\text { no**** }\end{array}$ \\
\hline gil19568098 & osmotic stress-activated protein kinase & 921 & 26 & 1 \\
gil120676 & $\begin{array}{l}\text { glyceraldehyde-3-phosphate } \\
\text { dehydrogenase }\end{array}$ & 325 & 12 & 3 \\
gil1419092 & glutamine synthetase (cytosolic) & 299 & 12 & 2 \\
gil3021506 & isocitrate dehydrogenase (NAD $\left.{ }^{+}\right)$ & 177 & 9 & 2 \\
gil40036995 & beta-tubulin & 130 & 8 & 1 \\
gil78191448 & ADP/ATP translocator-like & 122 & 6 & 1 \\
gil50058115 & actin & 84 & 4 & 2 \\
\hline
\end{tabular}

Cell suspensions were treated with $\mathrm{NaCl}(250 \mathrm{mM})$ for $5 \mathrm{~min}$. Protein extracts were immunoprecipitated with anti-NtOSAK antibodies or pre-immune serum as a control. Proteins present in the immunocomplex were separated by SDS-PAGE. Coomassie-stained protein bands were excised from the gel and analyzed by ESI-MS-MS/MS after in-gel digestion with trypsin. Results were used to search the NCBI (National Center for Biotechnology Information) database using the MASCOT search engine from Matrixscience.com under the tax on restriction of Viridiplantae. The table encloses a list of proteins selectively co-immunoprecipitated with NtOSAK, but not with the preimune serum, in response to $\mathrm{NaCl}$ treatment.

*Protein scores are derived from ions scores as a non-probabilistic basis for ranking protein hits.

${ }^{* *}$ Number of peptides sequenced de novo found to be derived from a given protein.

*** Band numbers correspond to figure in supplemental data 1

Results are from one of three representative experiments. 


\section{REFERENCES}

1. Besson-Bard, A., Gravot, A., Richaud, P., Auroy, P., Duc, C. and Gaymard, F. (2009) Taconnat L., Renou, J-P., Pugin, A. and Wendehenne, D. Nitric oxide contributes to cadmium toxicity in Arabidopsis thaliana by promoting cadmium accumulation in roots and by up-regulating genes related to iron uptake. Plant Physiol. 149, 1302-1315

2. Lamattina, L., García-Mata, C., Graziano, M. and Pagnussat, G. (2003) Nitric oxide: the versatility of an extensive signal molecule. Annu. Rev. Plant Biol. 54, 109-136

3. Wilson, I.D., Neill, S.J. and Hancock, J.T. (2008) Nitric oxide synthesis and signalling in plants. Plant Cell Environ. 31, 622-631

4. Besson-Bard, A., Pugin, A. and Wendehenne, D. (2008) New Insights into nitric-oxide signaling in plants. Annu. Rev. Plant Biol. 59, 21-39

5. Delledonne, M. (2005) NO news is good news for plants. Curr. Opin. Plant Biol. 8, 390-396

6. Wendehenne, D., Durner, J. and Klessig, D.F. (2004) Nitric oxide: a new player in plant signalling and defence responses. Curr. Opin. Plant Biol. 7, 449-455

7. Besson-Bard, A., Astier, J., Rasul, S., Wawer, I, Dubreuil-Maurizi, C., Jeandroz, S. and Wendehenne, D. (2009) Current view of nitric oxide-responsive genes in plants. Plant Sci. 177, 302-309

8. Palmieri, M.C., Lindermayr, C., Bauwe, H., Steinhauser, C. and Durner, J. (2010) Regulation of plant glycine decarboxylase by S-nitrosylation and glutathionylation. Plant Physiol. 152, 1514-1528

9. Holtgrefe, S., Gohlke, J., Starmann, J., Druce, S., Klocke, S., Altmann, B., Wojtera, J., Lindermayr, C. and Scheibe, R. (2008) Regulation of plant cytosolic glyceraldehyde 3-phosphate dehydrogenase isoforms by thiol modifications. Physiol. Plant. 133, 211228

10. Lindermayr, C., Saalbach, G. and Durner, J. (2005) Proteomic identification of Snitrosylated proteins in Arabidopsis. Plant Physiol. 13, 921-30

11. Lindermayr, C., Saalbach, G., Bahnweg, G. and Durner, J. (2006) Differential inhibition of Arabidopsis methionine adenosyltransferases by protein S-nitrosylation. J. Biol. Chem. 281, 4285-91

12. Belenghi, B., Romero-Puertas, M.C., Vercammen, D., Brackenier, A., Inze, D., Delledonne, M. and Van Breusegem, F. (2007) Metacaspase activity of A. thaliana is regulated by S-nitrosylation of a critical cysteine residue. J. Biol. Chem. 282, 13521358

13. Tada, Y., Spoel, S.H., Pajerowska-Mukhtar, K., Mou, Z., Song, J., Wang, C., Zuo, J. and Dong, X. (2008) Plant immunity requires conformational charges of NPR1 via Snitrosylation and thioredoxins. Science 321, 952-956

14. Wang, Y.Q., Feechan. A, Yun. B.W, Shafiei, R., Hofmann, A., Taylor, P., Xue, P., Yang, F.Q., Xie, Z.S., Pallas, J.A., Chu, C.C. and Loake, G.J. (2009) S-Nitrosylation of AtSABP3 Antagonizes the Expression of Plant Immunity. J Biol Chem. 284, 21312137

15. Romero-Puertas, M.C., Laxa, M., Mattè, A., Zaninotto, F., Finkemeier, I., Jones, A.M., Perazzolli, M., Vandelle, E., Dietz, K.J. and Delledonne, M. (2007) Snitrosylation of peroxiredoxin II E promotes peroxynitrite-mediated tyrosine nitration. Plant Cell 19, 4120-4130

16. Serpa, V., Vernal, J., Lamattina, L., Grotewold, E., Cassia, R. and Terenzi, H. (2007) Inhibition of AtMYB2 DNA-binding by nitric oxide involves cysteine S-nitrosylation. Biochem. Biophys Res. Commun. 361, 1048-1053 
17. Courtois, C., Besson, A., Dahan, J., Bourque, S., Dobrowolska, G., Pugin, A. and Wendehenne, D. (2008) Nitric oxide signalling in plants: interplays with $\mathrm{Ca}^{2+}$ and protein kinase. J. Exp. Bot. 59, 155-163

18. Yamamoto, A., Katou, S., Yoshioka, H., Doke, N. and Kawakita, K. (2004) Involvement of nitric oxide generation in hypersensitive cell death induced by elicitin in tobacco cell suspension culture. J. Gen. Plant Pathol. 70, 85-92

19. Zhang, A., Jiang, M., Zhang, J., Ding, H., Xu, S., Hu, X. and Tan, M. (2007) Nitric oxide induced by hydrogen peroxide mediates abscisic acid-induced activation of the mitogen-activated protein kinase cascade involved in antioxidant defense in maize leaves. New Phytol. 175, 36-50

20. Pagnussat, G.C., Lanteri, M.L., Lombardo, M.C. and Lamattina, L. (2004) Nitric oxide mediates the indole acetic acid induction activation of a mitogen-activated protein kinase cascade involved in adventitious root development. Plant Physiol. 135, 279-286

21. Lamotte, O., Courtois, C., Dobrowolska, G., Besson, A., Pugin, A. and Wendehenne, D. (2006) Mechanisms of nitric-oxide-induced increase of free cytosolic $\mathrm{Ca}^{2+}$ concentration in Nicotiana plumbaginifolia cells. Free Radic. Biol. Med. 40, 13691376

22. Clarke, A., Desikan, R., Hurst, R.D., Hancock, J.T. and Neill, S.J. (2000) NO way back: nitric oxide and programmed cell death in Arabidopsis thaliana suspension cultures. Plant J. 24, 667-677

23. Klessig, D.F., Durner, J., Noad, R., Navarre, D.A., Wendehenne, D., Kumar, D., Zhou, J.M., Shah, J., Zhang, S., Kachroo, P., Trifa, Y., Pontier, D., Lam, E. and Silva, H. (2000) Nitric oxide and salicylic acid signalling in plant defense. Proc. Natl. Acad. Sci. USA 97, 8849-8855

24. Lanteri, M.L., Pagnussat, G.C. and Lamattina, L. (2006) Calcium and calciumdependent protein kinases are involved in nitric oxide- and auxin-induced adventitious root formation in cucumber. J. Exp. Bot. 57, 1341-1351

25. Besson-Bard, A., Courtois, C., Gauthier, A., Dahan, J., Dobrowolska, G., Jeandroz, S., Pugin, A. and Wendehenne, D. (2008) Nitric oxide in plants: production and cross-talk with $\mathrm{Ca}^{2+}$ signalling. Mol Plant 1, 218-228

26. Otvös, K., Pasternak, T.P., Miskolczi, P., Domoki, M., Dorjgotov, D., Szucs, A., Bottka, S., Dudits, D. and Fehér, A. (2005) Nitric oxide is required for, and promotes auxin-mediated activation of, cell division and embryogenic cell formation but does not influence cell cycle progression in alfalfa cell cultures. Plant J. 43, 849-860

27. Boudsocq, M. and Lauriere, C. (2005) Osmotic signaling in plants. Multiple pathways mediated by emerging kinase families. Plant Physiol. 138, 1185-1194

28. Halford, N.G. and Hey, S.J. (2009) Snf1-related protein kinases (SnRKs) act within an intricate network that links metabolic and stress signalling in plants. Biochem. J. 419, 247-259

29. Hrabak, E.M., Chan, C.W.M., Gribskov, M., Harper, J.F., Choi, J.H., Halford, N., Kudla, J., Luan, S., Nimmo, H.G., Sussman, M.R., Thomas, M., Walker-Simmons, K., Zhu, J.K. and Harmon, A. (2003). The Arabidopsis CDPK-SnRK superfamily of protein kinases. Plant Physiol. 132, 666-680

30. Fujii, H. and Zhu, J.K. (2009) Arabidopsis mutant deficient in 3 abscisic acidactivated protein kinases reveals critical roles in growth, reproduction, and stress. Proc. Natl. Acad. Sci. USA 106, 8380-8385

31. Fujita, Y., Nakashima, K., Yoshida, T., Katagiri,T., Kidokoro, S., Kanamori, N., Umezawa, T., Fujita, M., Maruyama, K., Ishiyama, K., Kobayashi, M., Nakasone, S., Yamada, K., Ito, T., Shinozaki, K. and Yamaguchi-Shinozaki, K. (2009) Three SnRK2 
protein kinases are the main positive regulators of abscisic acid signaling in response to water stress in Arabidopsis. Plant Cell Physiol. 50, 2123-2132

32. Nakashima, K., Fujita, Y., Kanamori, N., Katagiri, T., Umezawa, T., Kidokoro, S., Maruyama, K., Yoshida, T., Ishiyama, K., Kobayashi, M., Shinozaki, K. and Yamaguchi-Shinozaki, K. (2009) Three Arabidopsis SnRK2 protein kinases, SRK2D/SnRK2.2, SRK2E/SnRK2.6/OST1 and SRK2I/SnRK2.3, involved in ABA signaling are essential for the control of seed development and dormancy. Plant Cell Physiol. 50, 1345-1363

33. Yoshida, R., Hobo, T., Ichimura, K., Mizoguchi, T., Takahashi, F., Aronso, J., Ecker, J.R. and Shinozaki, K. (2002) ABA-activated SnRK2 protein kinase is required for dehydration stress signaling in Arabidopsis. Plant Cell Physiol. 43, 1473-1483

34. Umezawa, T., Yoshida, R., Maruyama, K., Yamaguchi-Shinozaki, K. and Shinozaki, K. (2004) SRK2C, a SNF1-related protein kinase 2, improves drought tolerance by controlling stress-responsive gene expression in Arabidopsis thaliana. Proc. Natl. Acad. Sci. USA. 101, 17306-17311

35. Vlad, F., Rubio, S., Rodrigues, A., Sirichandra, C., Belin, C., Robert, N., Leung, J., Rodriguez, P.L., Laurière, C. and Merlot, S. (2009) Protein phosphatases 2C regulate the activation of the Snf1-related kinase OST1 by abscisic acid in Arabidopsis. Plant Cell 21, 3170-3184

36. Umezawa, T., Sugiyama, N., Mizoguchi, M., Hayashi, S., Myouga, F., YamaguchiShinozaki, K., Ishihama, Y., Hirayama, T. and Shinozaki, K. (2009) Type 2C protein phosphatases directly regulate abscisic acid-activated protein kinases in Arabidopsis. Proc. Natl. Acad. Sci. USA. 106, 17588-1793

37. Belin, C., de Franco, P.O., Bourbousse, C., Chaignepain, S., Schmitter, J.M., Vavasseur, A., Giraudat, J., Barbier-Brygoo, H. and Thomine, S. (2006) Identification of features regulating OST1 kinase activity and OST1 function in guard cells. Plant Physiol. 141, 1316-1327

38. Burza, A.M., Pekala, I., Sikora, J., Siedlecki, P., Małagocki, P., Bucholc, M., Koper, L., Zielenkiewicz, P., Dadlez, M. and Dobrowolska, G. (2006) Nicotiana tabacum osmotic stress-activated kinase is regulated by phosphorylation on Ser-154 and Ser158 in the kinase activation loop. J. Biol. Chem. 281, 34299-34311

39. Kelner, A., Pekala, I., Kaczanowski, S., Muszynska, G., Hardie, D.G. and Dobrowolska G. (2004) Biochemical characterization of the tobacco 42-kD protein kinase activated by osmotic stress. Plant Physiol. 136, 3255-3265

40. Hsu, M.F. and Meng, T.C. (2010) The enhancement of insulin responsiveness by nitric oxide-mediated inactivation of protein tyrosine phosphatases. J. Biol. Chem. 285, 7919-7928

41. Curcio, M.F., Batista, W.L., Linares, E., Nascimento, F.D., Moraes, M.S., Borges, R.E., Sap, J., Stern, A.I. and Monteiro, H.P. (2010) Regulatory effects of nitric oxide on Src kinase, FAK, p130Cas, and receptor protein tyrosine phosphatase alpha (PTPalpha): A role for the cellular redox environment. Antioxid Redox Signal. in press

42. Chen, Y.Y, Chu, H.M., Pan, K.T., Teng, C.H., Wang, D.L., Wang, A.H., Khoo, K.H. and Meng, T.C. (2008) Cysteine S-nitrosylation protects protein-tyrosine phosphatase $1 B$ against oxidation-induced permanent inactivation. J. Biol. Chem. 283, 35265-3572

43. Barrett, D.M., Black, S.M., Todor, H., Schmidt-Ullrich, R.K., Dawson, K.S. and Mikkelsen, R.B. (2005) Inhibition of protein-tyrosine phosphatases by mild oxidative stresses is dependent on S-nitrosylation. J. Biol. Chem. 280, 14453-14461 
44. Beck, K.F., Eberhardt, W., Frank, S., Huwiler, A., Messmer, U.K., Mühl, H. and Pfeilschifter, J. (1999) Inducible NO synthase: role in cellular signalling. J. Exp. Biol. 202, 645-653

45. Lander, H.M., Jacovina, A.T., Davis, R.J. and Tauras, J.M. (1996) Differential activation of mitogen-activated protein kinases by nitric oxide-related species. J. Biol. Chem. 271, 19705-19709

46. Park, H.S., Yu, J.W., Cho, J.H., Kim, M.S., Huh, S.H., Ryoo, K. and Choi, E.J. (2004) Inhibition of apoptosis signal-regulatin kinase 1 by nitric oxide through a thiol redox mechanism. J. Biol. Chem. 279, 7584-7590

47. Zhang, S. and Klessig, D.F. (1997) Salicylic acid activates a 48-kD MAP kinase in tobacco. Plant Cell 9, 809-824

48. Sell, S., Lindermayr, C. and Durner, J. (2008) Identification of S-nitrosylated proteins in plants. Methods. Enzym. 440, 283-292

49. He, P., Shan, L., and Sheen, J. (2007) The use of protoplasts to study innate immune responses. Methods Mol. Biol. 354, 1-9

50. Mikolajczyk, M., Awotunde, O.S., Muszyńska, G., Klessig, D.F. and Dobrowolska, G. (2000) Osmotic stress induces rapid activation of a salicylic acid-induced protein kinase and a homolog of protein kinase ASK1 in tobacco cells. Plant Cell 12, 165-178

51. Gould, K., Lamotte, O., Klinguer, A., Pugin, A. and Wendehenne, D. (2003) Nitric oxide production by tobacco leaves: a general stress responses ? Plant Cell Environ. 26, 1851-1862

52. Jaffrey, S.R., Erdjument-Bromage, H., Ferris, C.D., Tempst, P. and Snyder, S.H. (2001) Protein S-nitrosylation: a physiological signal for neuronal nitric oxide. Nat. Cell Biol. 3, 193-197

53. Hara, M.R., Agrawal, N., Kim, S.F., Cascio, M.B. and Fujimuro, M. (2005) Snitrosylated GAPDH initiates apoptotic cell death by nuclear translocation following Siah1 binding. Nat. Cell. Biol. 7, 665-674

54. Stamler, J.S., Lamas, S. and Fang, F.C. (2001) Nitrosylation: the prototypic redoxbased signalling mechanism. Cell 106, 675-683

55. Nakajima, H., Amano, W., Kubo, T., Fukuhara, A., Ihara, H., Azuma, Y.T., Tajima, H., Inui, T., Sawa, A. and Takeuchi, T. (2009) Glyceraldehyde-3-phosphate dehydrogenase aggregate formation participates in oxidative stress-induced cell death. J. Biol. Chem. 284, 34331-41

56. Kobayashi, Y., Yamamoto, S., Minami, H., Kagaya, Y. and Hattori, T. (2004) Differential activation of the rice sucrose nonfermenting1-related protein kinase2 family by hyperosmotic stress and abscisic acid. Plant Cell 16, 1163-1177

57. Furihata, T., Maruyama, K., Fujita, Y., Umezawa, T., Yoshida, R., Shinozaki, K. and Yamaguchi-Shinozaki, K. (2006) Abscisic acid-dependent multisite phosphorylation regulates the activity of a transcription activator AREB1. Proc. Natl. Acad. Sci. USA 103, 1988-1993

58. Kobayashi, Y., Murata, M., Minami, H., Yamamoto, S., Kagaya, Y., Hobo, T., Yamamoto, A. and Hattori, T. (2005) Abscisic acid-activated SNRK2 protein kinases function in the gene-regulation pathway of ABA signal transduction by phosphorylating ABA response element-binding factors. Plant J. 44, 939-949

59. Shin, R., Alvarez, S., Burch, A.Y., Jez, J.M. and Schachtman, D.P. (2007) Phosphoproteomic identification of targets of the Arabidopsis sucrose nonfermentinglike kinase SnRK2.8 reveals a connection to metabolic processes. Proc. Natl. Acad. Sci. USA. 104, 6460-6465

60. Browning, K.S. (1996) The plant translational apparatus. Plant Mol. Biol. 32, 107144. 
61. Sirover, M.A. (1999) New insights into an old protein: the functional diversity of mammalian glyceraldehyde-3-phosphate dehydrogenase. Biochim. Biophys. Acta. 432, 159-184

62. Hancock, J.T., Henson, D., Nyirenda, M., Desikan, R., Harrison, J., Lewis, M., Hughes, J. and Neill, S.J. (2005) Proteomic identification of glyceraldehyde 3phosphate dehydrogenase as an inhibitory target of hydrogen peroxide in Arabidopsis. Plant Physiol. Biochem. 43, 828-835

63. Morigasaki, S., Shimada, K., Ikner, A., Yanagida, M. and Shiozaki, K. (2008) Glycolytic enzyme GAPDH promotes peroxide stress signaling through multistep phosphorelay to a MAPK cascade. Mol. Cell. 30, 108-113

64. Benhar, M. and Stamler, J.S. (2005) A central role for S-nitrosylation in apoptosis. Nat. Cell Biol. 7, 645-646

65. Singh, P., Salih, M., Leddy, J.J. and Tuana, B.S. (2004) The muscle-specific calmodulin-dependent protein kinase assembles with the glycolytic enzyme complex at the sarcoplasmic reticulum and modulates the activity of glyceraldehyde-3phosphate dehydrogenase in a $\mathrm{Ca}^{2+} /$ calmodulin-dependent manner. J Biol Chem. 279, 35176-82 
B) Biochemical Journal Immediate Publication. Published on 16 Apr 2010 as manuscript BJ20100492

Figure 1

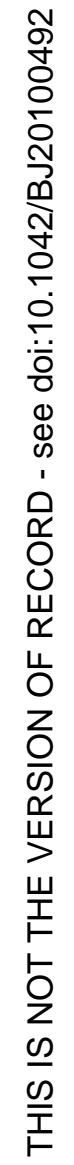

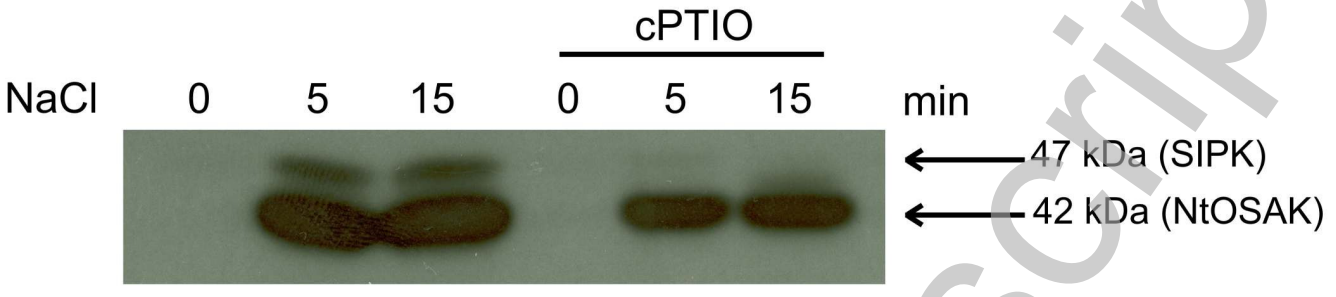


Figure 2

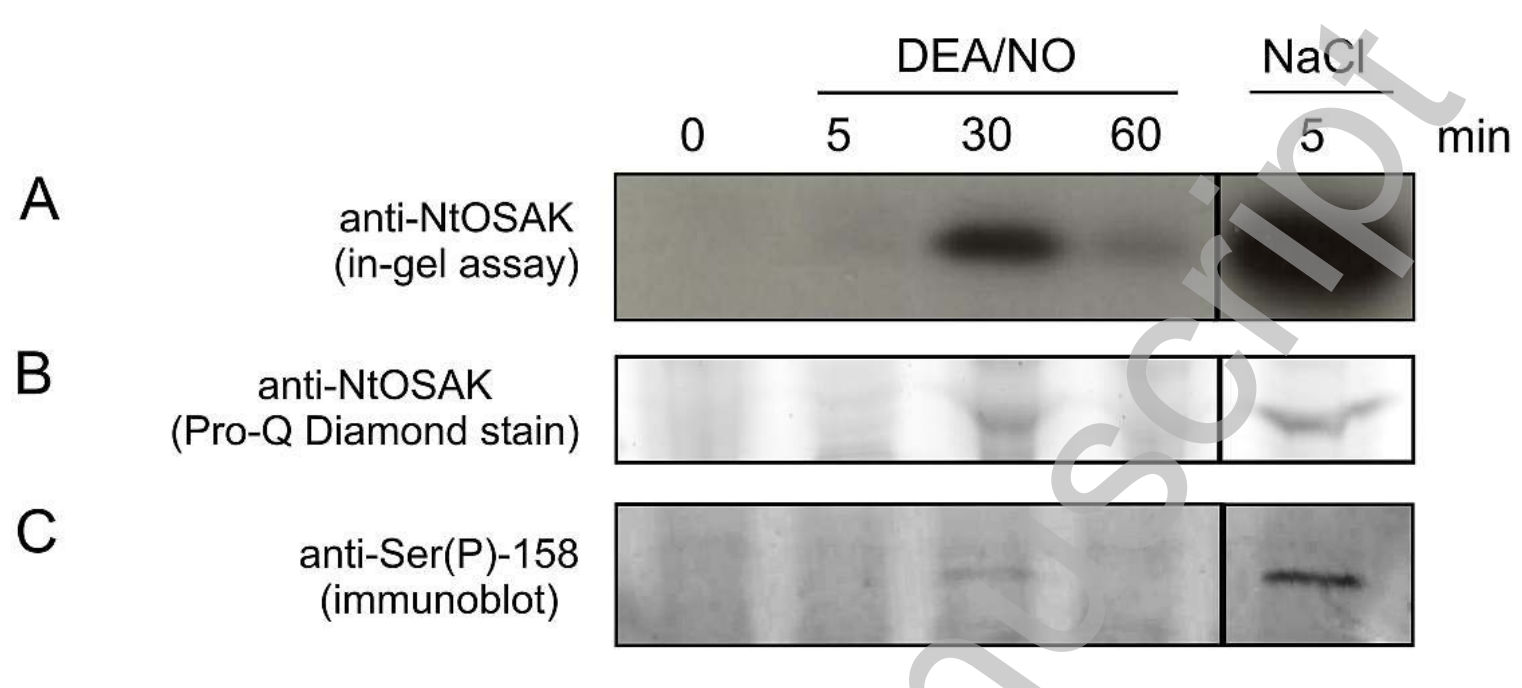


Figure 3

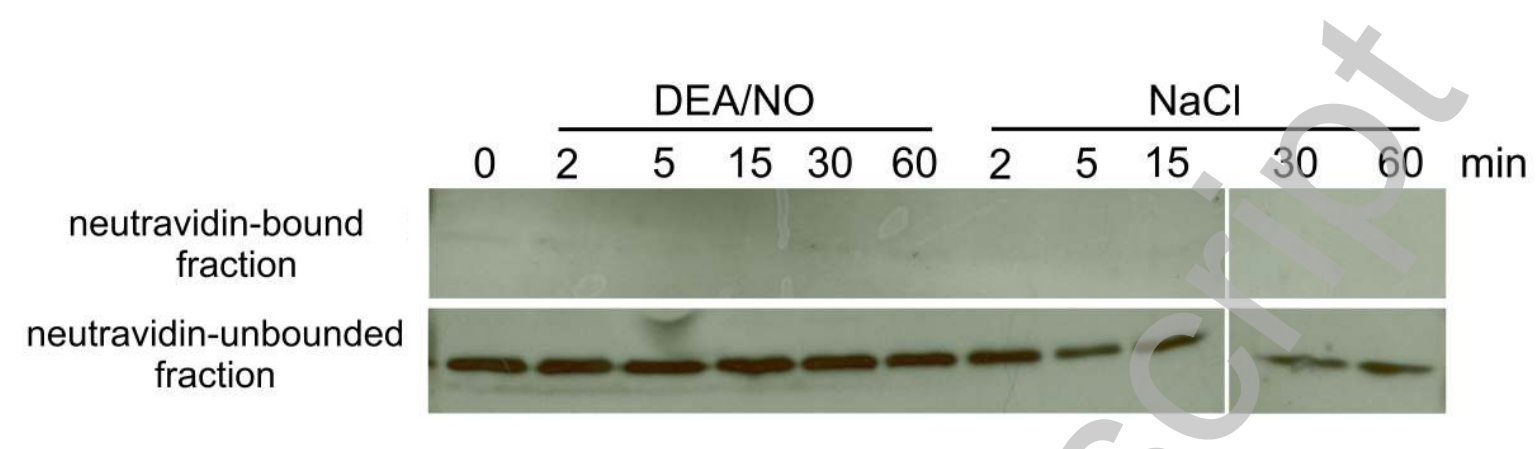

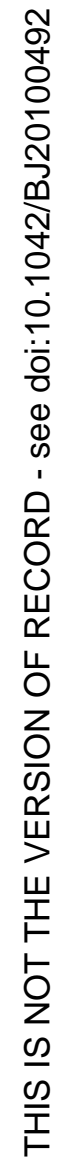


Figure 4

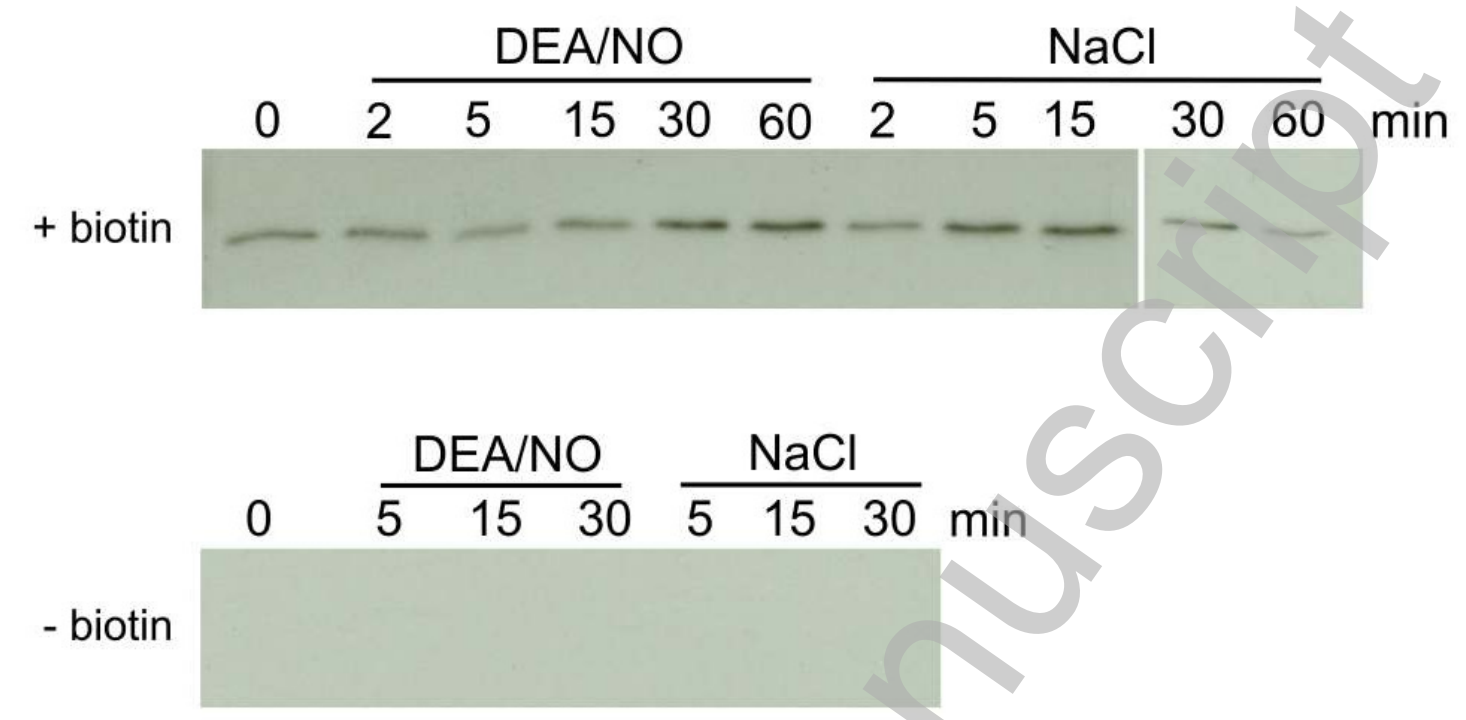


Biochemical Journal Immediate Publication. Published on 16 Apr 2010 as manuscript BJ20100492

Figure 5

A

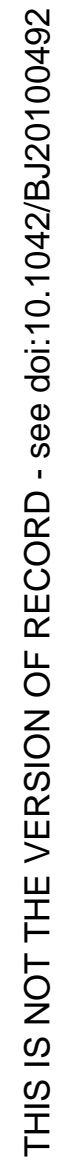

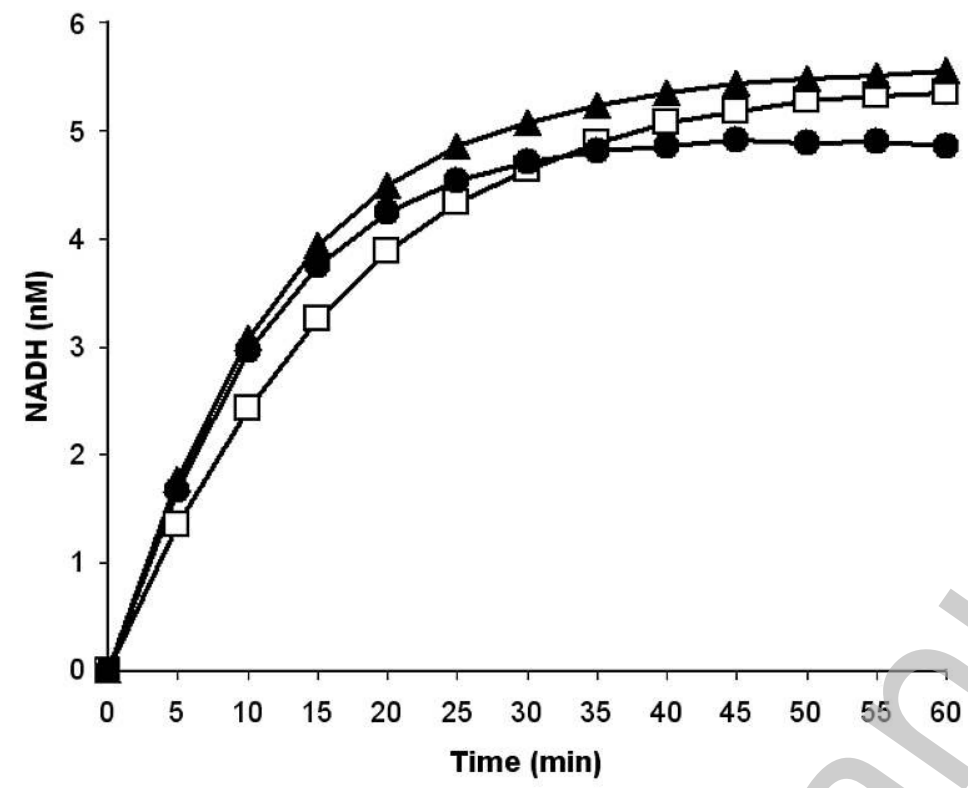

$\rightarrow$ control $\longrightarrow 50 \mu \mathrm{M}$ DEA/NO $\rightarrow-250 \mathrm{mM} \mathrm{NaCl}$

B

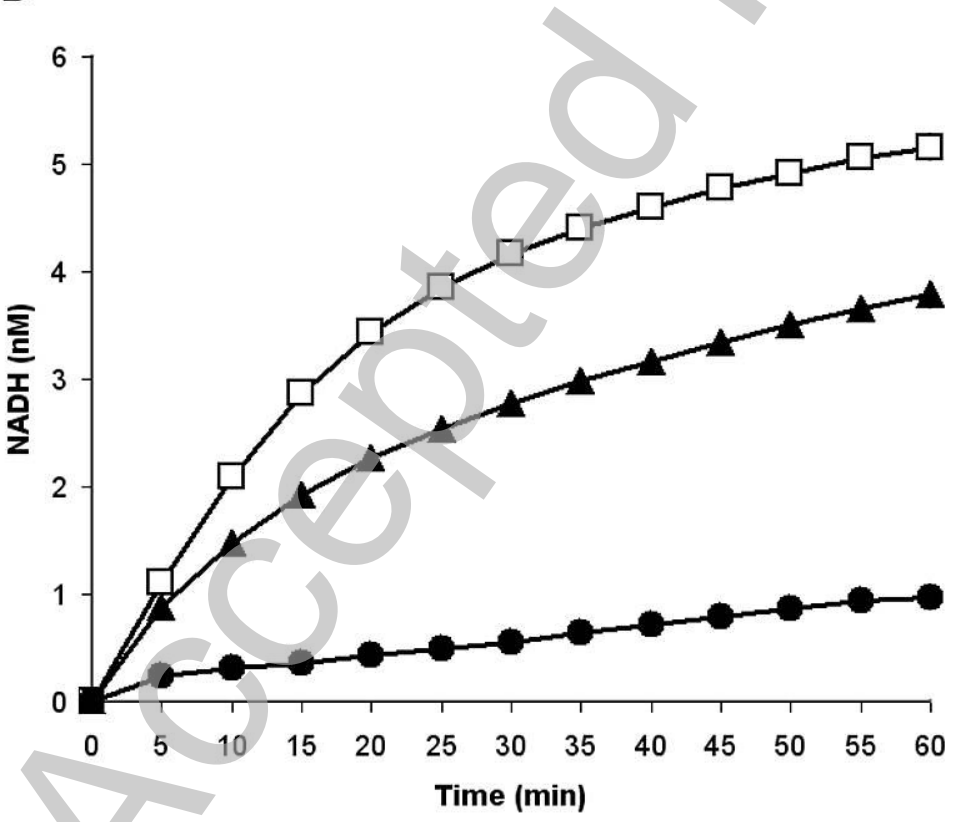

$\neg$ control $\neg 50 \mu \mathrm{M}$ DEA/NO $\bullet-500 \mu \mathrm{M}$ DEA/NO

Licenced copy. Copying is not permitted, except with prior permission and as allowed by law.

(C) 2010 The Authors Journal compilation (c) 2010 Portland Press Limited 
Figure 6

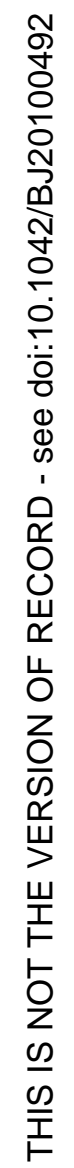

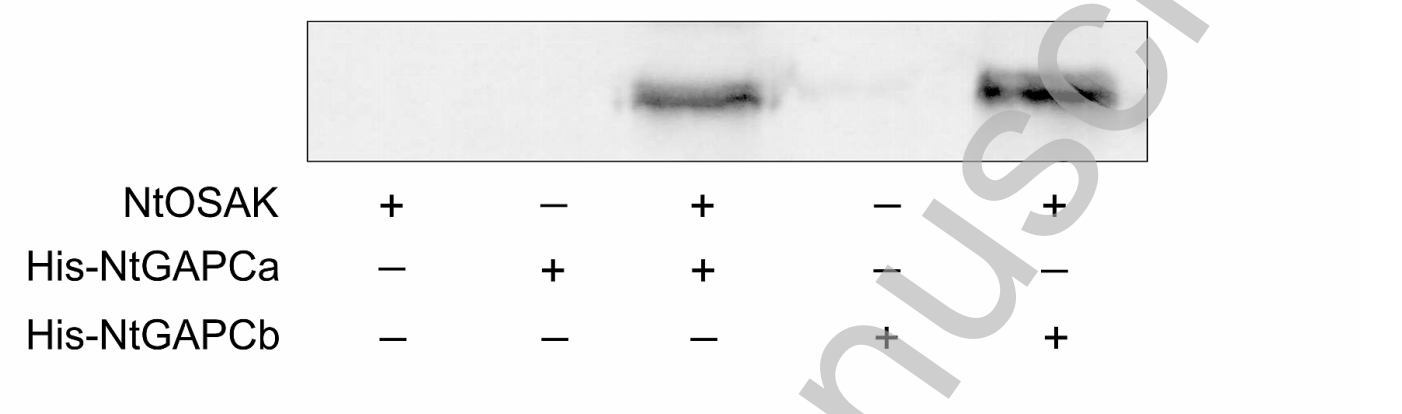


Figure 7
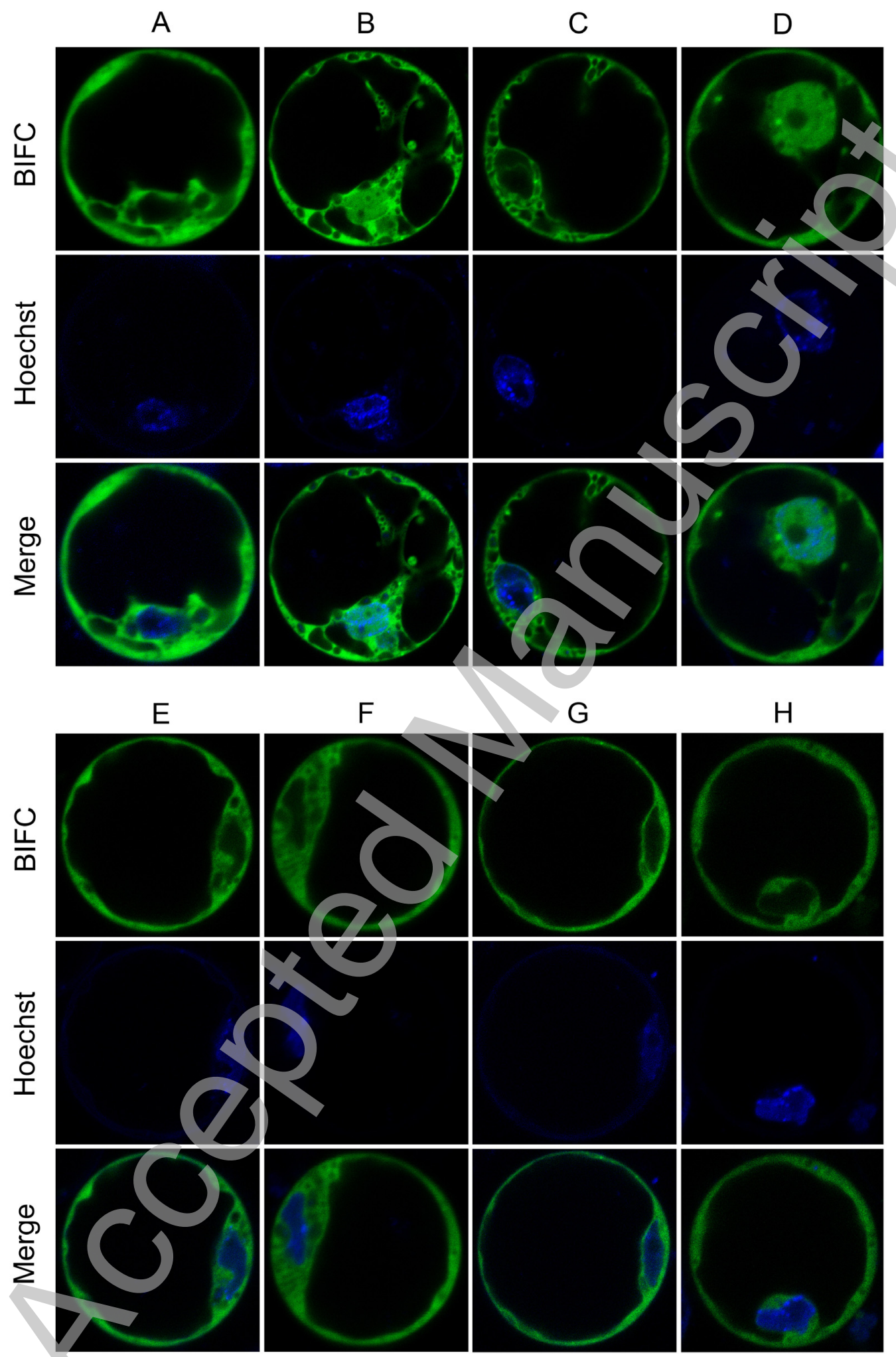

Licenced copy. Copying is not permitted, except with prior permission and as allowed by law. (C) 2010 The Authors Journal compilation (c) 2010 Portland Press Limited 